\title{
Adjoint tomography of the crust and upper mantle structure beneath the Kanto region using broadband seismograms
}

\author{
Takayuki Miyoshi ${ }^{12^{*}}$, Masayuki Obayashi ${ }^{3}$, Daniel Peter ${ }^{4}$, Yoko Tono ${ }^{5}$ and Seiji Tsuboi ${ }^{6}$
}

\begin{abstract}
A three-dimensional seismic wave speed model in the Kanto region of Japan was developed using adjoint tomography for application in the effective reproduction of observed waveforms. Starting with a model based on previous travel time tomographic results, we inverted the waveforms obtained at seismic broadband stations from 140 local earthquakes in the Kanto region to obtain the $\mathrm{P}$ - and S-wave speeds $V_{p}$ and $V_{s}$. Additionally, all centroid times of the source solutions were determined before the structural inversion. The synthetic displacements were calculated using the spectral-element method (SEM) in which the Kanto region was parameterized using 16 million grid points. The model parameters $V_{p}$ and $V_{s}$ were updated iteratively by Newton's method using the misfit and Hessian kernels until the misfit between the observed and synthetic waveforms was minimized. Computations of the forward and adjoint simulations were conducted on the K computer in Japan. The optimized SEM code required a total of 6720 simulations using approximately 62,000 node hours to obtain the final model after 16 iterations. The proposed model reveals several anomalous areas with extremely low $-V_{s}$ values in comparison with those of the initial model. These anomalies were found to correspond to geological features, earthquake sources, and volcanic regions with good data coverage and resolution. The synthetic waveforms obtained using the newly proposed model for the selected earthquakes showed better fit than the initial model to the observed waveforms in different period ranges within 5-30 s. This result indicates that the model can accurately predict actual waveforms.
\end{abstract}

Keywords: Seismic wave speed model, Adjoint tomography, Waveform inversion, Broadband seismogram, Kanto region

\section{Introduction}

The Japanese metropolitan area in the Kanto plain, which contains 40 million inhabitants, has a high disaster risk derived from the earthquake and volcanic activities related to the subduction of two oceanic plates, the Pacific (PAC) and Philippine Sea (PHS) plates, beneath the overriding tectonic plates (Fig. 1). Various types of earthquakes are associated with the convergence of these plates in the region (e.g., Hori 2006), such as interplate earthquakes on the upper surface of the PHS or PAC slab, intraslab earthquakes within the PHS or PAC slab, and inland earthquakes within the upper crust. The

\footnotetext{
*Correspondence: miyoshi@bosai.go.jp

${ }^{1}$ Earthquake Research Institute, University of Tokyo, 1-1-1 Yayoi, Bunkyo-ku, Tokyo 113-0032, Japan

${ }^{2}$ Present address: Earthquake and Tsunami Research Division, National Research Institute for Earth Science and Disaster Resilience, 3-1 Tennodai, Tsukuba, Ibaraki 305-0006, Japan

Full list of author information is available at the end of the article
}

1703 and 1923 great Kanto earthquakes (M8-class) have been considered typical examples of interplate earthquakes on the upper surface of the PHS slab and caused severe damage as a result of their strong shaking and major tsunamis. The 1923 event is the most recent destructive earthquake occurring beneath this area and took the lives of more than 100,000 people in the Kanto plain. Modern Japanese society in this metropolitan area has not experienced large earthquakes occurring in this area since the 1923 Kanto earthquake. Active faults have been identified in the basin despite the thick basin layer, the thickness of which reaches a maximum of approximately $4 \mathrm{~km}$ (e.g., Suzuki 1996). The active faults are candidate sources of future inland great earthquakes; however, it is not difficult to imagine that unknown faults are buried beneath the metropolitan area. Active volcanoes to the west of the Kanto plain may produce volcanic disasters on the same scale as the large eruption 

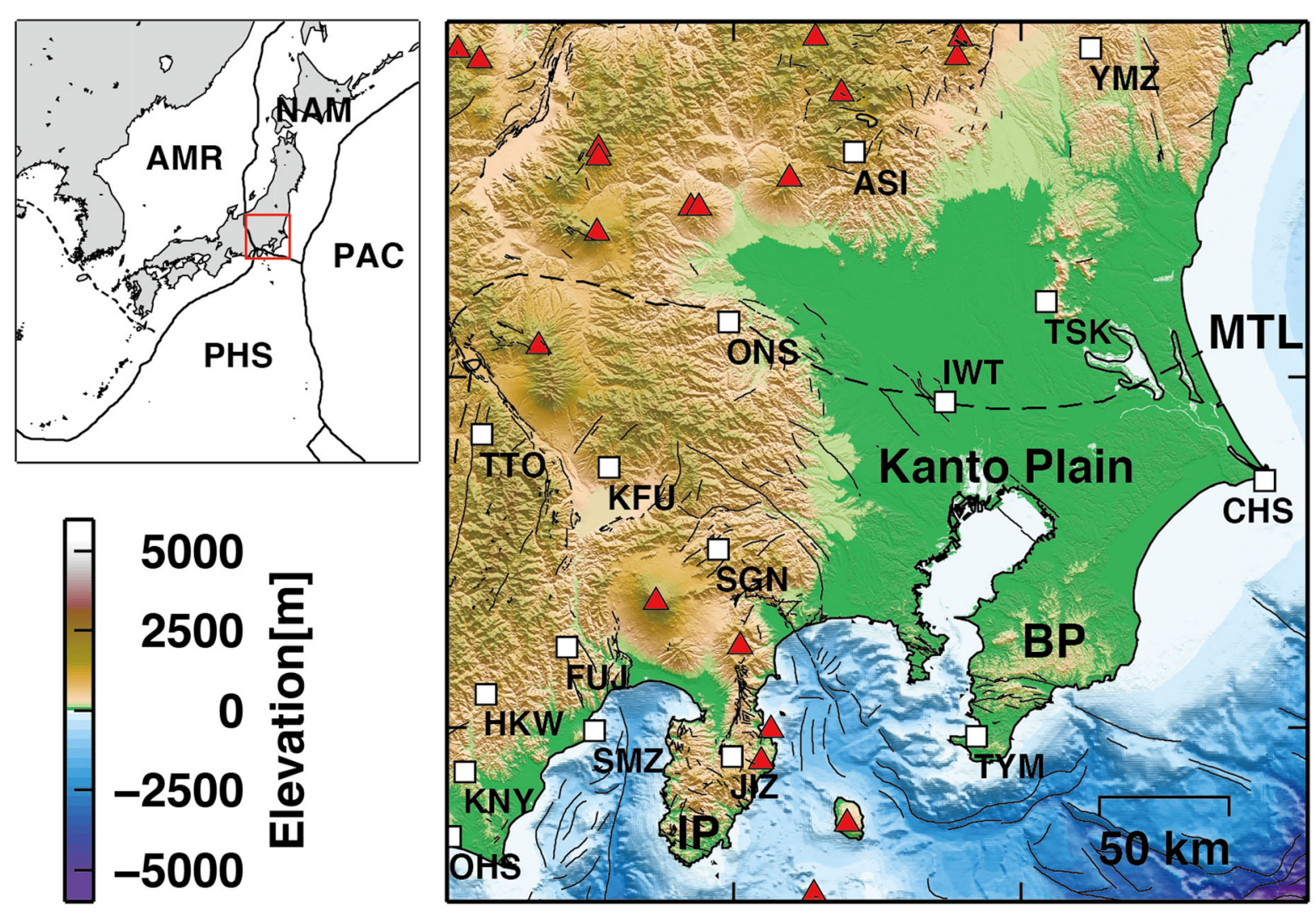

\section{$138^{\circ} \mathrm{E}$}

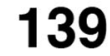

140

141

Fig. 1 Distribution of tectonic plates and topography of the study area. Open squares indicate the NIED F-net stations used in the present study. Red triangles denote active volcanoes. Thin black lines and the broken line denote active faults and the Median Tectonic Line (MTL), respectively. AMR, NAM, PAC, and PHS in the left figure indicate the Amur, North America, Pacific, and Philippine Sea plates, respectively. BP and IP in the right figure indicate the Boso and Izu Peninsulas

of Mt. Fuji in 1707. A detailed model of the threedimensional (3D) wave speed structure would greatly improve the present understanding of seismotectonics and volcanotectonics and enable the prediction of strong motion for future earthquakes occurring beneath the metropolitan area.

The crust and upper mantle structure, seismotectonics, subduction process, and other characteristics based on local tomography using travel time data of Pand $\mathrm{S}$-waves beneath the Kanto region have been reported (e.g., Kamiya and Kobayashi 2000, 2007; Matsubara et al. 2005; Nakajima et al. 2009; Nakajima and Hasegawa 2010). These results have contributed to the present geophysical understanding of the Kanto region. However, difficulties arise when observed seismograms are modeled using numerical simulations based on these structure models because it is unknown how the raybased tomographic results quantitatively reproduce observed waveforms. Therefore, seismic tomography based on wave theory would be a useful approach to address such difficulties.

From the viewpoint of strong motion prediction, Koketsu et al. $(2008,2009)$ proposed a modeling procedure of a $3 \mathrm{D}$ wave speed structure to evaluate the ground shaking produced by an earthquake. They used various types of databases, such as geophysical experiments, gravity surveys, geological investigations, and seismic observations of natural events, to develop a layered model of the Kanto basin. Yoshimoto and Takemura (2014) applied a realistic sedimentary structure of the Kanto basin to the Japan integrated velocity structure model (Koketsu et al. 2008) to reproduce the excitation and dispersion of the observed surface waves. These models reproduced the observed waveforms but were not suitable to assess the tectonic processes associated with seismic and volcanic activities, because they assumed the layered structure of a homogeneous isotropic media. 
Recent progress in supercomputer technology has enabled the calculation of accurate seismograms based on wave theory, which requires a large amount of computing resources. In addition to forward modeling, waveform inversion can be conducted by solving an inverse problem using efficient algorithms (e.g., Tarantola 1984, 1986; Geller and Hara 1993; Tromp et al. 2005). Waveform tomography has been developed as a powerful approach to infer the earth's structure. In waveform tomography, the adjoint method is commonly used. In this method, the gradients of misfit functions with respect to density, shear wave speed, and compressional wave speed are simply given by the interaction between the forward wavefields, which propagate from the source to the receivers, and the adjoint wavefields, which propagate from the receivers back to the source. For each earthquake, numerical simulations need to be conducted only twice: once for the construction of the forward and adjoint wavefields and once to obtain the gradients of the misfit function. Based on a combination of the spectral-element and adjoint methods, various wave speed models have been obtained in previous studies, including models of the Southern California crust (Tape et al. 2007, 2009, 2010), the western Pyrenees (Wang et al. 2016), the Australasian upper mantle (Fichtner et al. 2009), the European upper mantle (Zhu et al. 2012, 2015; Zhu and Tromp 2013), the East Asian crust and upper mantle (Chen et al. 2015), and the crust and upper mantle around the Japanese archipelago (Simute et al. 2016). Bozdag et al. (2016) conducted the first study in which a model of the entire crust and mantle of the earth was constructed using the iterative fullwaveform inversion technique. Waveform tomography has become a feasible method of revealing the heterogeneity of the earth's interior at various spatial scales. We used waveform tomography with iterative waveform inversion to obtain a fine structure model through the adjoint method, referred to as "adjoint tomography" (e.g., Tape et al. 2007, 2010).

In this study, a 3D seismic wave speed model of the Kanto region was constructed to overcome the problems mentioned above and enable an analysis of both tectonic features and waveform reproduction using seismograms of the period band between 5 and $30 \mathrm{~s}$ by adjoint tomography. We demonstrated how the initial and final wave speed structures could qualitatively reproduce seismograms in each frequency band and described the relation between the wave speed structure and tectonic phenomena. Although it is beyond the scope of the present work to predict short-period strong motions for the mitigation of earthquake disasters, the basin structure related to the excitation of surface waves is briefly discussed in the context of achieving strong motion prediction in the Kanto region.

\section{Methods/Experimental}

\section{Earthquake and broadband waveform data}

After the disastrous 1995 Hyogoken-nanbu (Kobe) earthquake, numerous seismographs were installed in Japan by the National Research Institute for Earth Science and Disaster Prevention (NIED; renamed the National Research Institute for Earth Science and Disaster Resilience in 2016). The installation of the broadband seismograph networks was started as the Fundamental Research on Earthquakes and Earth's Interior Anomaly (FREESIA) project, and the current full-range seismograph network of Japan (F-net) provides nationwide coverage with approximately 70 stations (e.g., Okada et al. 2004). These seismographs are mostly located in tunnels to reduce noise from various sources and observe the ground velocities of three components. The waveforms are recorded continuously and distributed to the public through the Internet. The instrument conditions are systematically monitored to maintain data quality (Kimura et al. 2015). The NIED provides an earthquake catalog of moment tensor solutions based on F-net seismograms for regional earthquakes in and around the Japanese archipelago (e.g., Kubo et al. 2002). In the F-net earthquake catalog, the centroid depth and moment tensor are determined; however, other parameters are fixed to rapid information reported by the Japan Meteorological Agency. The source parameters used in the present study are discussed in a later subsection.

The earthquakes were selected from the F-net earthquake catalog according to the following selection criteria. The events must have (1) occurred between 1998 and 2014, (2) a focal depth shallower than $80 \mathrm{~km}$, (3) a magnitude in the range of $4.0 \leq M_{W} \leq 5.5$, and (4) an average variance reduction of waveform fitting between the observed and synthetic waveforms larger than $85 \%$ once the source parameters have been determined. Based on these criteria, 140 earthquakes were selected for inversion data, with 18 events used to evaluate the tomographic results obtained in the present study. Figure 2 shows the selected events. The selected events were classified into three types from a tectonic viewpoint: interplate earthquakes with the $\mathrm{P}$-axis in the $\mathrm{E}-\mathrm{W}$ direction on the PAC slab, interplate earthquakes with the P-axis in the NW-SE direction on the PHS slab, and inland earthquakes of the upper crust. However, events that occurred in the upper crust beneath the Kanto basin could not be detected.

Broadband waveforms recorded at the F-net stations in and around the Kanto basin were used. A total of approximately 4400 seismograms with good quality were obtained at 16 stations for the 140 considered events. The velocity seismograms were integrated after removing the response of the seismometer from original 


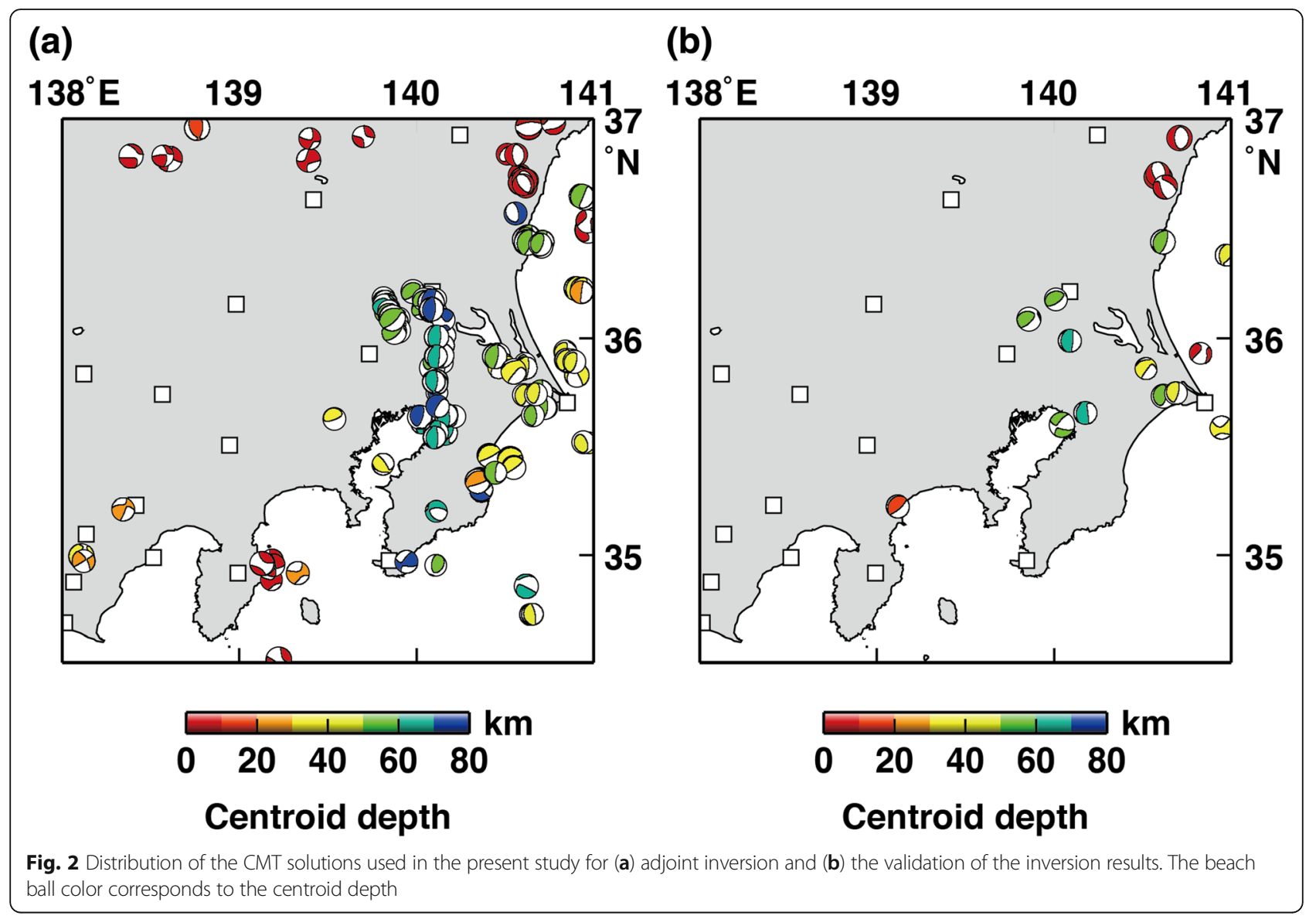

records to obtain the displacement time series in three components.

\section{Spectral-element method and initial model}

Both synthetic and observed waveforms had to be obtained to conduct adjoint tomography. Synthetic displacements were obtained using the spectral-element method (SEM), a numerical method to solve the equations of motion in the weak form precisely. In previous studies, the SEM was first applied to solve a fluid dynamics problem (Patera 1984) numerically and was later used in seismic wave simulations for a complex 3D structure at various scales (e.g., Komatitsch and Tromp 2002a, 2002b; Peter et al. 2011). We used the SPECFEM3D Cartesian program package (e.g., Peter et al. 2011), which has been developed as a parallel computing code to simulate seismic waves on a local scale.

A structure model in the Universal Transverse Mercator coordinate system with horizontal dimensions of $459 \mathrm{~km} \times 492 \mathrm{~km}$ and a depth of $120 \mathrm{~km}$ was considered to span the entire Kanto basin area and to include all selected earthquakes and F-net stations. The initial and iterative models assumed only a solid earth without the fluid parts. Some bias may be produced by neglecting the effect of the solid-fluid interface and the ocean on the waveforms for offshore events. However, this bias was expected to be negligibly small for the minimum period (5s) considered in this study because of the short distances the waves traveled. The presence of the oceans was mostly relevant for the dispersion of Rayleigh waves in the case of shallow events, as well as for free-surface reflected phases, such as PP, SS, and SP (e.g., Komatitsch and Tromp 2002b).

Absorbing boundary conditions were applied to the artificial boundaries of the horizontal and bottom surfaces (Clayton and Engquist 1977), and the topography was represented in the uppermost edges of the model. The initial P- and S-wave speed, $V_{p}$ and $V_{s}$, respectively, were based on the $3 \mathrm{D}$ travel time tomography model by Matsubara and Obara (2011), which resolved structures in the Japanese archipelago and off the coast by using the travel times of offshore events. The density $\rho$ was computed from $V_{p}$ for the initial model using an empirical relationship (e.g., Gardner et al. 1974; Brocher 2005). The relation $\rho=V_{p} / 6+5 / 3$ was used in this study. The density in the iterative model was updated using a scaling factor for the $V_{s}$-density relation $(\delta \ln \rho) /(\delta \ln$ $\left.V_{s}\right)=0.33$ (e.g., Montagner and Anderson 1989; Panning 
and Romanowicz 2006). The attenuation structure was estimated from the relation with $V_{s}$ (Olsen et al. 2003); that is, $Q_{\mu}$ was set to scale as 0.05 times $V_{s}$ (in meters per second). The attenuation structure $Q_{\kappa}$ related to the compressional wave was not taken into account in the inversion.

The mesh structure of the initial model in the present study is shown in Fig. 3. The mesh used in the SEM model contained approximately 230,000 elements with $1.6 \times 10^{7}$ grid points. Each element had $125(5 \times 5 \times 5)$ Gauss-Lobatto-Legendre points that share grid points with neighboring elements. The mesh had one doubling layer at a depth of approximately $40 \mathrm{~km}$ (Fig. 3). To accurately map the topography and bathymetry of the region to the mesh, a minimum element size of approximately $400 \mathrm{~m}$ at the upper boundary was chosen, and the mesh was coarsened to a maximum size of $8000 \mathrm{~m}$ at the lower boundary. The model area was extended from the area of interest shown in Figs. 1 and 2 as a safeguard against the reflection of waves from the artificial boundaries in addition to the absorbing condition. The simulation was accurate up to a minimum period of $2.6 \mathrm{~s}$. Because the mesh structure of the SEM model was maintained throughout the inversion, the minimum period could be longer than $2.6 \mathrm{~s}$ when the seismic wave speed in the iterative model was slower than that of the initial model. The initial and $i$ th iterative models are hereafter referred to $\mathbf{m}_{00}$ and $\mathbf{m}_{i}$, respectively.

The following earthquake source parameters were obtained from the F-net moment tensor catalog: the origin time, epicentral coordinates, centroid depth, moment tensor, and seismic moment. No information concerning the rupture duration was included in the F-net catalog, and the centroid time was fixed at the same value as the origin time. According to the analysis of the centroid moment tensor by Matsumura et al. (2006), the time difference between the origin and centroid times was on the order of a few seconds for local earthquakes in Japan. Obtaining the centroid moment solution using the 3D model had a high computational cost so only the centroid time was determined without estimating other

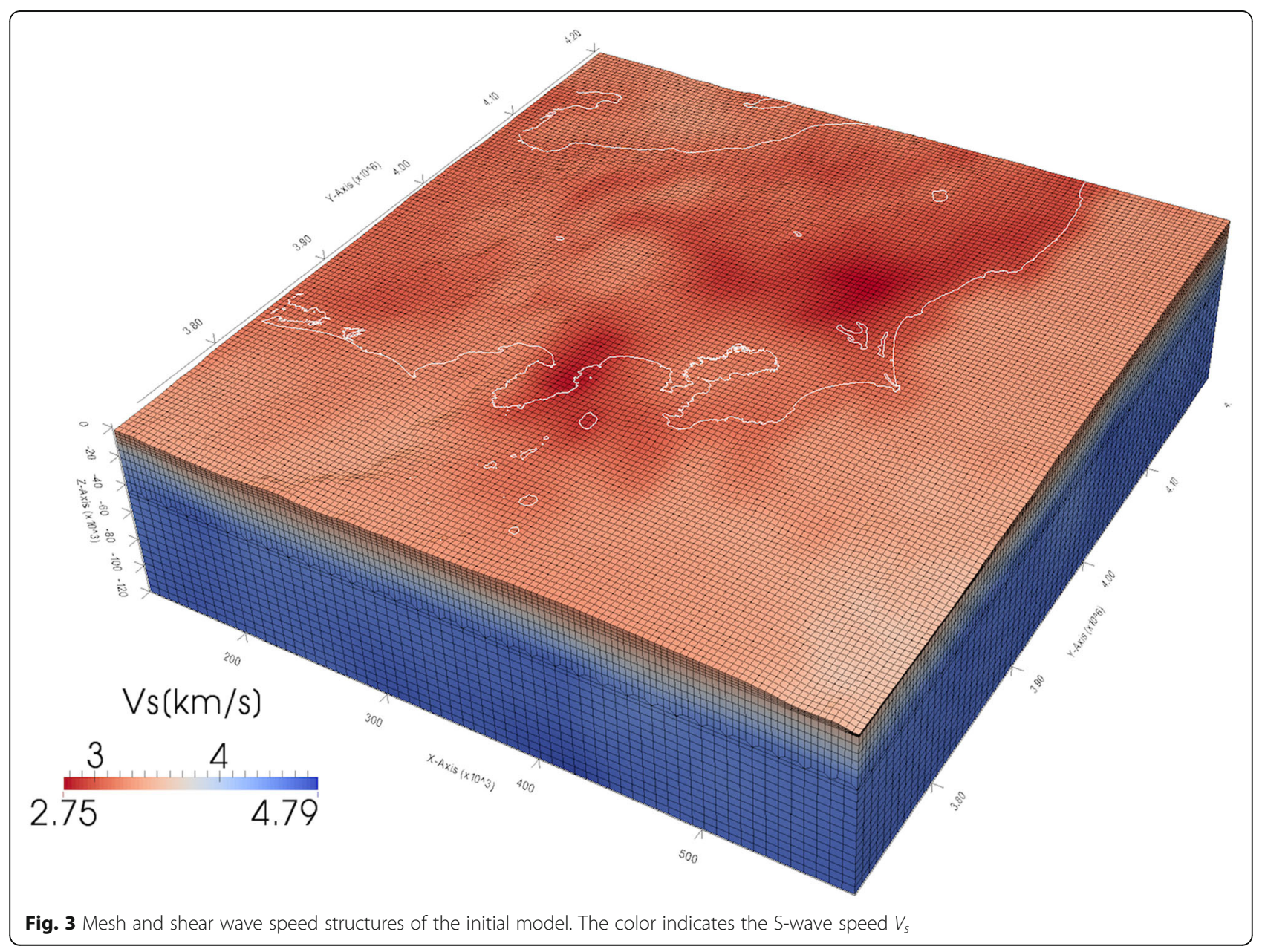


source parameters in this study. The difference between the origin and centroid times was assumed to be the average of the time shifts, which were defined as the time deviation between the observed and synthetic waveforms estimated using phase correlation for a packet of P-waves. The synthetic displacements calculated using the SEM for the initial model were compared with the observed waveforms in the period band of 5-30 s to estimate the lag times. Figure 4 shows a histogram of the time shifts for all events. Almost all time shifts were positive, indicating that the earthquakes have rupture times of a couple of seconds. Some events had negative time shifts, and these negative time shifts may have been caused by the poor estimation of the source parameters.

\section{Adjoint tomography procedure}

This subsection describes the adjoint tomography procedure used in the present study. Figure 5 shows a summary of the present inversion procedure, which was similar to that used in previous studies (Tape et al. 2010; Zhu et al. 2015). The adjoint tomography method is briefly discussed; more detail on the basic theory of adjoint tomography can be found in previous works (e.g., Tromp et al. 2005; Tape et al. 2007, 2010; Zhu et al. 2015). The wave speed model was iteratively updated by minimizing the misfit between the observed and synthetic waveforms. The model parameters were the P-and S-wave speeds $V_{p}$ and $V_{s}$ of the grid points, and the number of parameters in this model was approximately $1.6 \times 10^{7} \times 2$. The density and attenuation were updated

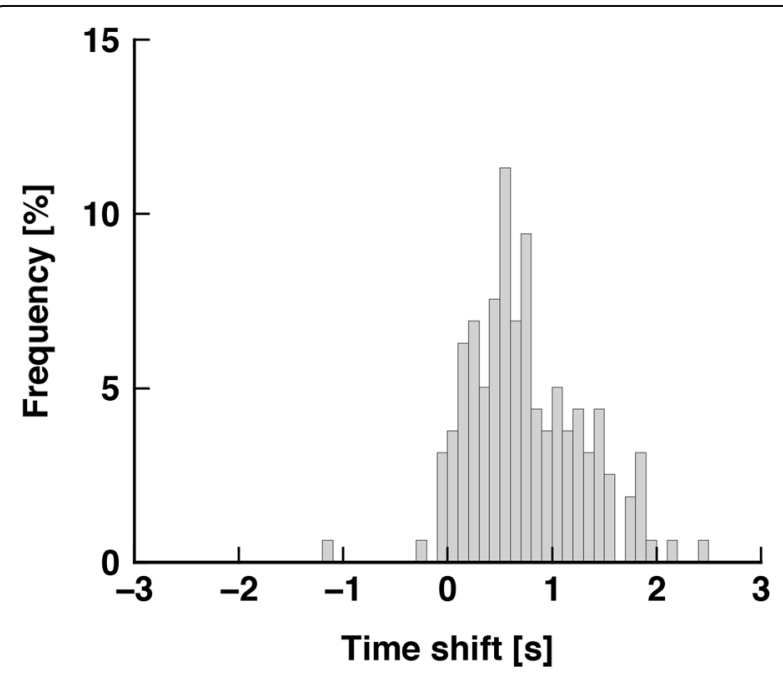

Fig. 4 Histogram of the time shift for source parameters used in the present study. The positive and negative values indicate positive and negative delay times from each origin time, respectively

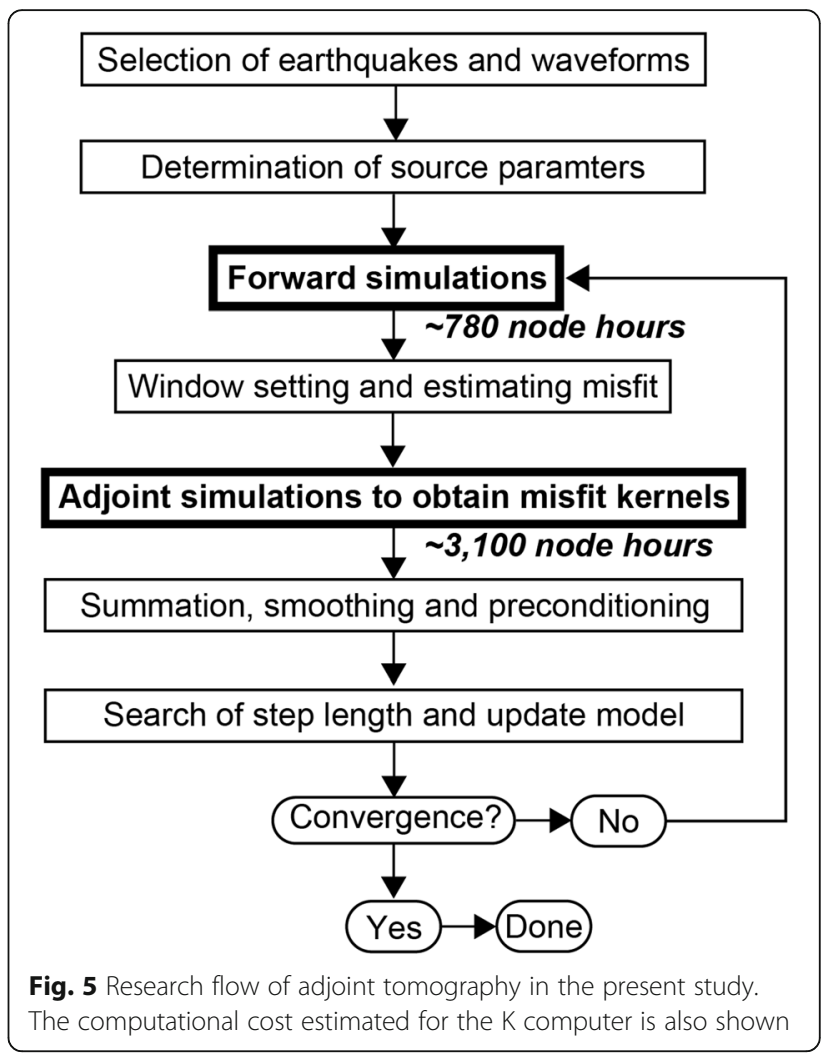

using the new $V_{s}$ value in each iteration according to the velocity-density and velocity-attenuation scaling relationships, respectively.

The waveforms for such a 3D SEM mesh structure were synthesized over a duration of $130 \mathrm{~s}$ with a time step of $0.005 \mathrm{~s}$ for each iteration to calculate the misfit function. The misfit function was calculated for the waveforms in the time windows of the seismic phases. The FLEXWIN algorithm developed by Maggi et al. (2009) was used to determine the time windows, in which multiple quantitative criteria, such as the crosscorrelation coefficient between the observed and synthetic waveforms, the time lag, and the signal-to-noise $(\mathrm{S} / \mathrm{N})$ ratio of the observation, were defined. We selected 2630 windows for the period between 20 and $30 \mathrm{~s}$ in the first iteration and over 4000 windows for the period between 5 and $30 \mathrm{~s}$ in the last iteration. The misfit function for the $i$ th window in a single trace was defined using the multitaper method (Zhou et al. 2004; Tape et al. 2010) as

$$
F_{i}(\boldsymbol{m})=\int_{-\infty}^{\infty} \frac{h_{i}(\omega)}{H_{i}}\left[\frac{\Delta T_{i}(\omega, \boldsymbol{m})}{\sigma_{i}}\right]^{2} \mathrm{~d} \omega
$$

where $\sigma_{i}$ is the estimated uncertainty associated with the travel time measurement, $\Delta T_{i}(\omega, \boldsymbol{m})=T_{i}^{o b s}(\omega)-T_{i}$ 
$(\omega, \boldsymbol{m})$ indicates the frequency-dependent travel time difference between the observed and synthetic waveforms, $h_{i}(\omega)$ is a window in the frequency domain, and $H_{i}$ is a normalization constant. To minimize the misfit function using the adjoint method, the timereversed technique was applied to this function, and its product was used as the adjoint source in the backward simulation from each station to the source (e.g., Tromp et al. 2005). After the adjoint wavefield was calculated, the event kernel was obtained as the interaction between the forward and adjoint wavefields in each event. This yielded sensitivity kernels for compressional and shear wave speeds for all events, as well as an approximate Hessian kernel, which was regarded as the second derivative of the misfit function.

All event kernels were summed, and smoothing was applied to obtain the misfit kernels for $V_{p}$ and $V_{s}$. The approximate Hessian kernels were used as preconditioners in Newton's method (e.g., Tape et al. 2007; Fichtner 2010), and the $i$ th model was updated using the gradient $g(\mathbf{m})$ of the misfit function and the step length $\alpha$ as

$$
\boldsymbol{m}_{i+1}=\boldsymbol{m}_{i}-\alpha H^{-1}(\boldsymbol{m}) g(\boldsymbol{m}),
$$

where $H(\mathbf{m})$ is a Hessian kernel. The gradient and the Hessian of the misfit function $\boldsymbol{F}$ are given respectively as follows:

$$
\begin{aligned}
& g(\boldsymbol{m})=\left.\frac{\partial \boldsymbol{F}}{\partial \boldsymbol{m}}\right|_{\boldsymbol{m}}, \\
& H(\boldsymbol{m})=\left.\frac{\partial^{2} \boldsymbol{F}}{\partial \boldsymbol{m} \partial \boldsymbol{m}}\right|_{\boldsymbol{m}} .
\end{aligned}
$$

Here, $g(\mathbf{m})$ and $H(\mathbf{m})$ were smoothed before updating the model. Prominent values of the kernels were prevented from appearing around sources and receivers by the smoothing effect. Because these Hessian kernels represented the approximation of the diagonal elements in the Hessian matrix, the Hessian kernel acted like a normalization factor within the sensitive area. The adjoint state method (Tarantola 1984; Plessix 2006) was employed to obtain the gradient, and the approximate Hessian was calculated as the vector inner product and convolution of the forward and adjoint accelerations as follows:

$$
\tilde{H}(\boldsymbol{x})=\int \partial_{t}^{2} \boldsymbol{s}(\boldsymbol{x}, t) \cdot \partial_{t}^{2} \boldsymbol{s}^{\dagger}(\boldsymbol{x}, T-t) \mathrm{d} t
$$

where $\boldsymbol{s}$ and $\boldsymbol{s}^{\dagger}$ are the forward and adjoint displacement wavefields, respectively (Zhu et al. 2015). The model was updated using Eq. (2) assuming $H(\boldsymbol{x}) \approx \tilde{H}(\boldsymbol{x})$. The step length $\alpha$ was set to values ranging from 1 to $5 \%$ in increments of $1 \%$ based on the waveform misfits. The seismograms of a representative subset of 10 earthquakes were calculated for five candidate models, and the misfit was evaluated for each model to obtain the optimal step length. The model with the minimum misfit value was selected as the updated model. For example, $\alpha=4 \%$ was selected in the first iteration.

Although the principal goal of this study was to obtain synthetic waveforms that agree well with the observed waveforms in the period range of 5-30 s, the inversion was initiated with waveforms in the period band of 20 $30 \mathrm{~s}$ to prevent cycle skipping. Period bands, including shorter periods, were then used in the following stages: $10-30,8-30$, and $5-30 \mathrm{~s}$. The stage was updated after the convergence of the iterative inversion was achieved at each stage. The achieved convergence was determined using the variance reduction (VR) (e.g., Kubo et al. 2002) when (i) the difference between the summations of the VR values from all events in the current and former iterations was less than $1 \%$ or (ii) the current VR value was larger than that of the previous iteration. The variance reduction is defined as:

$$
V R_{i}(\boldsymbol{m})=1-\frac{\int_{-\infty}^{\infty} w_{i}(t)[d(t)-s(t, \boldsymbol{m})]^{2} d t}{\int_{-\infty}^{\infty} w_{i}(t)[d(t)]^{2} d t} \text { for the } i \text { th window } w_{i}(t),
$$

where $d(t)$ is the amplitude of the data and $s(t, \boldsymbol{m})$ is the synthetic waveform of model $\mathbf{m}$. The VR values ranged from $-\infty$ to 1 , with the latter representing a perfect fit. The left panels in Fig. 6b-e show the frequency distributions of the VR values over the full time length based on $\mathbf{m}_{00}$ for four period bands. The waveform fitting of the longer period bands was better than that of the shorter bands. There was a difference between the observed and synthetic waveforms even in the longer band (Fig. 6e), so it was reasonable to first consider the seismograms of the longer period band.

\section{Computational costs}

The present analysis required only 140 pairs of forward and backward simulations to obtain the gradient of the misfit function in every iteration. However, it still required a high computational cost and extensive time to obtain the final model despite using the adjoint technique. Sufficient computer resources had to be acquired to conduct the calculations. In both the forward and adjoint simulations, the model region was divided into 256 $(16 \times 16)$ slices in the horizontal plane, and one processor performed the calculations from bottom to top in each slice. Parallel computing was used to conduct the calculation for the 256 slices. The $\mathrm{K}$ computer at the RIKEN Advanced Institute for Computational Science in Kobe, Japan, was used for the large computations. The K 
(a)

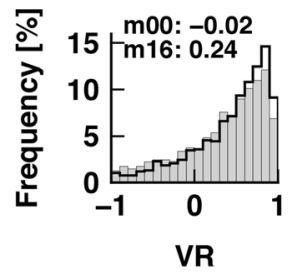

(b)

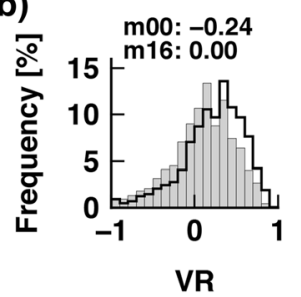

(c)

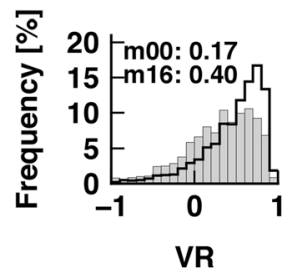

(d)

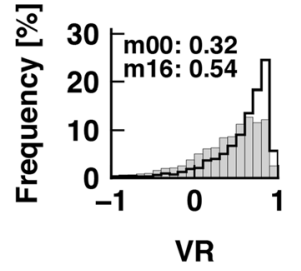

(e)

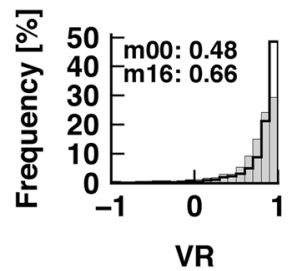

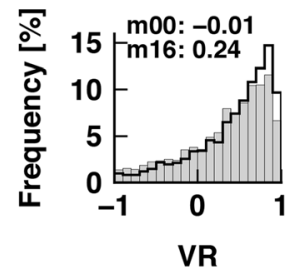
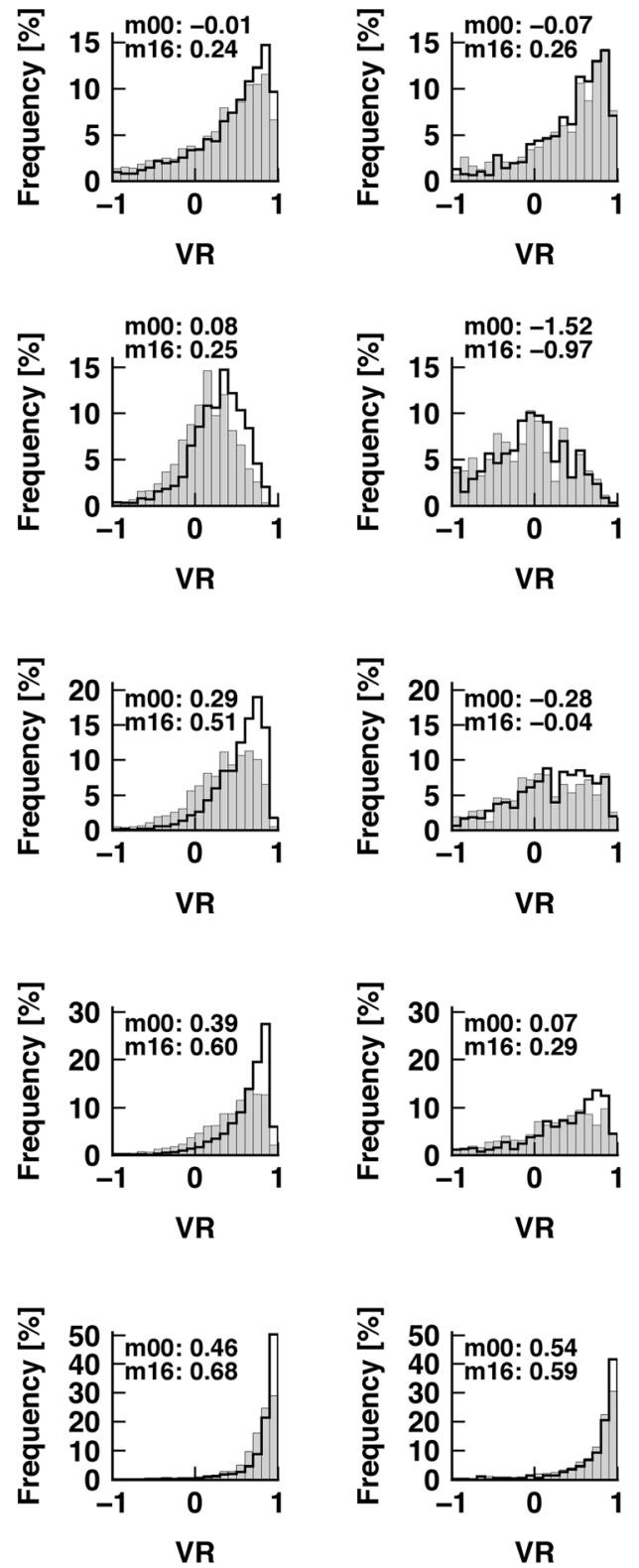

Fig. $\mathbf{6}$ Histograms of the variance reduction VR for the initial and final models $\mathbf{m}_{00}$ and $\mathbf{m}_{16}$. $\mathbf{a}$ All windows for the period range of $5-30 \mathrm{~s}$. $\mathbf{b}$ Full waveform for the period range of 5-30 s. c Full waveform for the period range of 8-30 s. d Full waveform for the period of 10-30 s. e Full waveform for the period range of 20-30 s. The left, center, and right panels show all events, events that occurred at depths greater than $30 \mathrm{~km}$, and events that occurred at depths less than $30 \mathrm{~km}$, respectively. The gray bars and black outlines represent the VR values of $\mathbf{m}_{00}$ and $\mathbf{m}_{16}$, respectively. The VR values can range from $-\infty$ to 1. The average $V R$ values are also shown in each panel

computer had a very large number of nodes $(82,944)$, and each node or central processing unit had eight cores. Forward simulations using the SEM on the K computer have been previously implemented for global modeling by Tsuboi et al. (2016). They optimized the source code for the $\mathrm{K}$ computer and successfully modeled waveforms with an accuracy of $2 \mathrm{~s}$. In the present study, the forward and adjoint wavefields were simulated using source code optimized in the same manner as Tsuboi et al. (2016) on 32 nodes (256 cores) with a flat message passing interface parallel computing model. It took approximately $10 \mathrm{~min}$ to conduct a single forward simulation and approximately $40 \mathrm{~min}$ to obtain a single event kernel using 256 cores. When sufficient free nodes 
were available, 140 forward or adjoint simulations were conducted simultaneously using 8192 cores. In each iteration, the computational costs to obtain a forward wavefield and a single event kernel were approximately $780 \times 8$ and $3100 \times 8$ core hours, respectively. Zhu et al. (2015) reported that the computational cost of the kernel calculation was twice that of the forward simulation; however, the present kernel computational cost was four times that of the forward simulation. This highlighted the well-optimized forward computation concerning the original kernel computation. In general, the cost proportion may depend on the difference between the optimization levels of the source codes of the forward and adjoint parts.

\section{Results}

\section{Waveform improvement}

The final seismic wave speed model was obtained after 16 iterations. Figure 7 shows the line search procedure for the step length in the first iteration and the iterative transition of the VR values and the period bands used in each iteration. In the first iteration, a step length of $4 \%$ was selected by comparing the VR values of five models to produce the first iterative model $\mathbf{m}_{01}$ (Fig. 7a). The VR values increased gradually with each iteration (Fig. 7b). Figure 6 shows the results of fitting the synthetic waveform to the observed waveform for $\mathbf{m}_{00}$ and $\mathbf{m}_{16}$. For the waveforms within the time windows, the fitting was improved in the final model for the period range of 5-30 s (Fig. 6a). Full seismograms were analyzed for the four considered period bands to quantitatively evaluate the waveform fitting. The waveform fitting was improved by the iterative process in all period ranges (Fig. 6b-e). The VR value in the period range of $5-30 \mathrm{~s}$ was improved by $24 \%$, corresponding to VR values of -0.24 and 0.00 for $\mathbf{m}_{00}$ and $\mathbf{m}_{16}$, respectively. The depth dependence of the waveform fitting was also analyzed with a depth threshold of $30 \mathrm{~km}$. The fitting was improved for events occurring at depths both greater (center panels in Fig. 6) and less (right panels in Fig. 6) than $30 \mathrm{~km}$. The fitting of the deeper events was much better than that of the shallower events for $\mathbf{m}_{16}$, as indicated by the VR values. We concluded from these results that the proposed iterative process could more accurately reproduce waveforms with longer periods or waveforms of deeper events than it could reproduce waveforms with shorter periods or waveforms of shallower events.

The observed waveforms for the considered earthquakes were compared with the theoretical ones to perform a detailed investigation of how the waveforms were changed by the inversion. Figures 8 and 9 show the three components of the displacements of example waveforms obtained at the JIZ station. The vertical cross sections of the shear wave speeds of $\mathbf{m}_{00}$ and $\mathbf{m}_{16}$ and their differences along the source and the receiver are also shown in Figs. 8 and 9. As shown in Fig. 8, the radial and vertical components of the $\mathbf{m}_{00}$ waveform differed from those of the observed waveform, such as those at the arrival of some of the phases near the $\mathrm{S}$-wave, whereas the $\mathbf{m}_{16}$ waveforms reproduced the observation well. Because the shear wave speed between the source and the receiver was slower than that of the $\mathbf{m}_{00}$ waveform, the $\mathbf{m}_{16}$ waveform was slightly delayed relative to the $\mathbf{m}_{00}$ waveform. As shown in Fig. 9, the three components of the synthetic waveform for $\mathbf{m}_{00}$ were not well fitted to the observed ones, and the waveform components for $\mathbf{m}_{16}$ matched better than those of $\mathbf{m}_{00}$ near the arrival of the $\mathrm{S}$-wave. A faster shear wave speed model between the source and the receiver was inferred in $\mathbf{m}_{16}$ in comparison with that in $\mathbf{m}_{00}$, and this contributed to the improvement of the waveform models. As shown in Figs. 8 and 9, the theoretical waveforms accurately reproduced the observed ones near the arrival of the P- and S-waves.
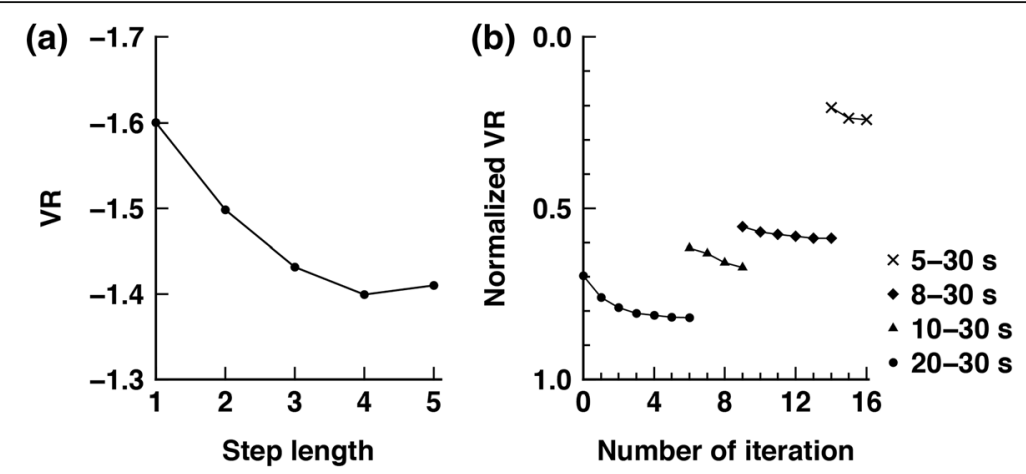

Fig. 7 Waveform fitting in the inversion process. a Step length search in the first iteration. b Waveform misfit between the observed and synthetic waveforms in each iteration. The fitting value is normalized by the fitting value of the first iteration of each period band. The period band used in each iteration is also shown 
(a)

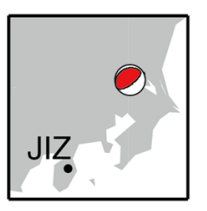

(b)

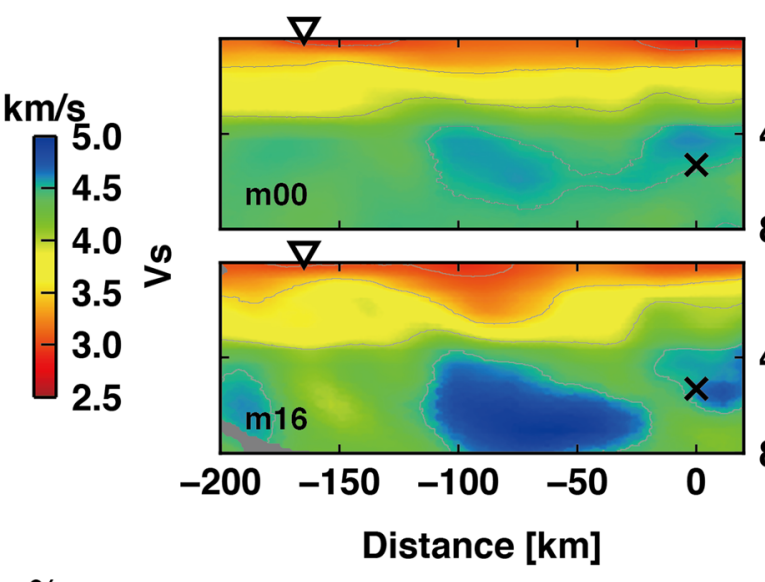

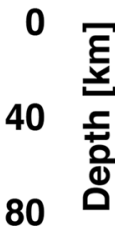

0

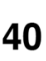

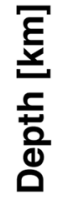

(c)

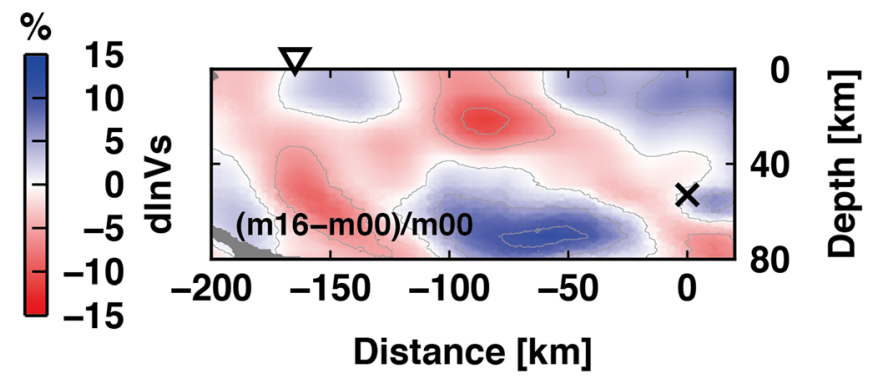

(d)
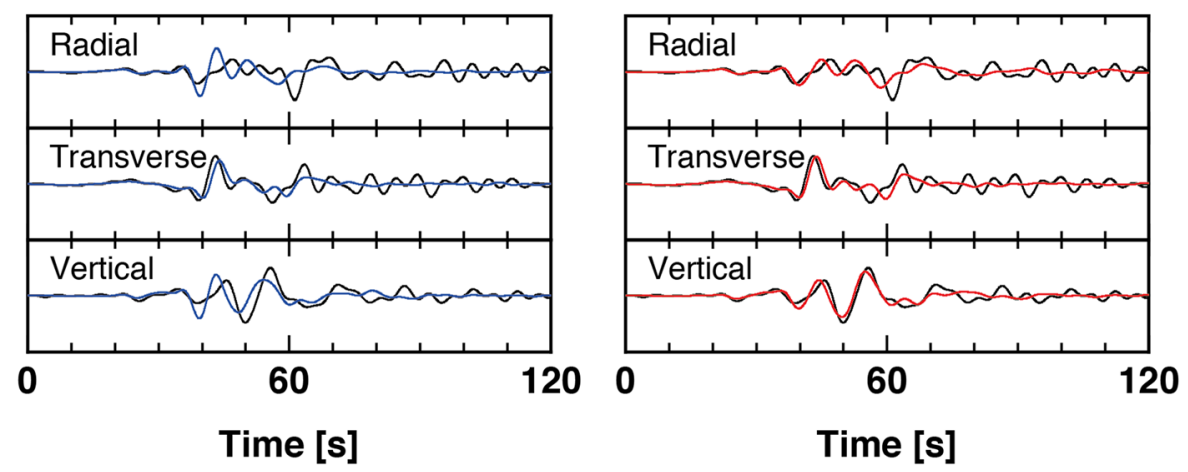

Fig. 8 Shear wave speed models and waveforms for the earthquake on the PHS (June 2, 2007; $M_{W}$ 4.5). a Source and receiver. b Vertical cross section of $V_{s}$ for $\mathbf{m}_{00}$ and $\mathbf{m}_{16}$. $\mathbf{c}$ Vertical cross section of the difference between the $V_{s}$ values for $\mathbf{m}_{00}$ and $\mathbf{m}_{16}$. $\mathbf{d}$ Waveform comparisons. The gray areas in (b) and (c) indicate areas of low data coverage. The crosses and inverted triangles in (b) and (c) show the location of the earthquake and station in (a), respectively. The black, blue, and red lines in (d) indicate the observed, $\mathbf{m}_{00}$, and $\mathbf{m}_{16}$ waveforms, respectively

However, the waveforms around the later arrivals of the $\mathrm{S}$-wave were not well fitted to the observed ones, because the time windows were set around the $\mathrm{P}$ - and $\mathrm{S}$ waves. Later phases must be added as inversion window data to modify the seismograms, such as the surface waves derived from the basin; this remains a task for future studies.

\section{Seismic wave speed model}

This section describes the wave speed models obtained in the present study. The average lateral speeds of $\mathbf{m}_{00}$ and $\mathbf{m}_{16}$ were examined, the wave speeds of $\mathbf{m}_{00}$ and $\mathbf{m}_{16}$ were compared, and the absolute wave speeds in the depth slices and their deviations from the average were assessed. First, some distinct characteristics of the wave speed models are discussed. Figure 10a shows the average wave speeds of $\mathbf{m}_{00}$ and $\mathbf{m}_{16}$ at each depth. The average shear and compressional wave speeds of $\mathbf{m}_{16}$ were both lower than those of $\mathbf{m}_{00}$ (Fig. 10a). The wave speeds of $\mathbf{m}_{00}$ obtained at the grid points were compared with those of $\mathbf{m}_{16}$ to examine the differences between $\mathbf{m}_{00}$ and $\mathbf{m}_{16}$ in detail. The $V_{s}$ and $V_{p}$ values of $\mathbf{m}_{16}$ were distributed widely around the $V_{s}$ and $V_{p}$ values of $\mathbf{m}_{00}$, respectively (Fig. 10b, c). Based on a comparison of the 
(a)

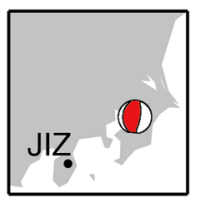

(d)

(c)
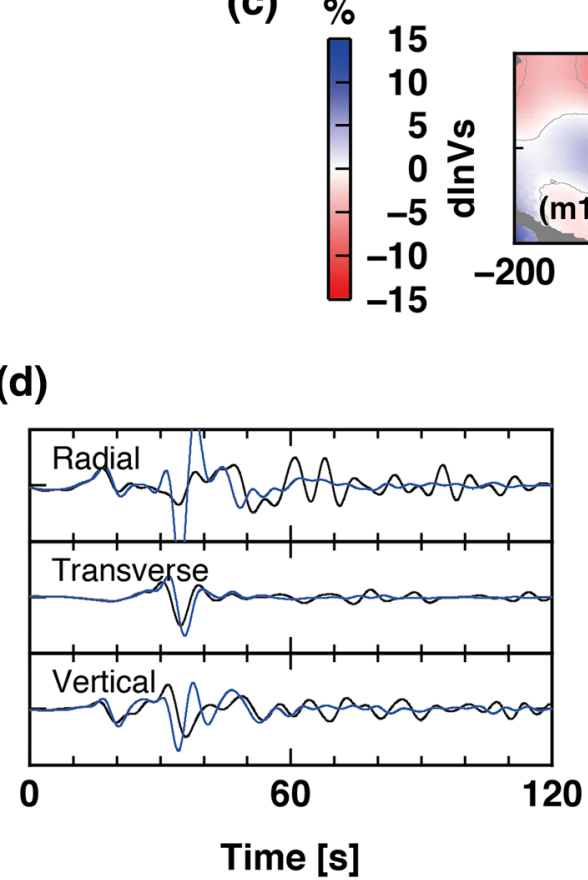

(b)

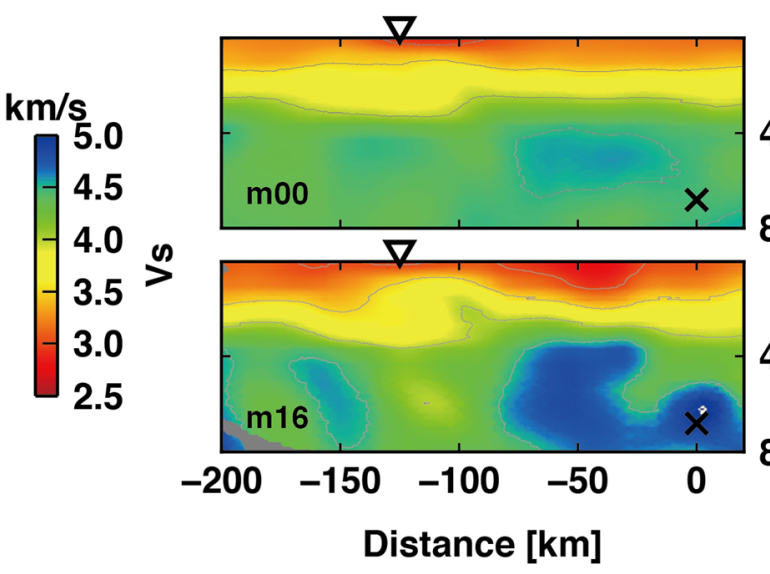

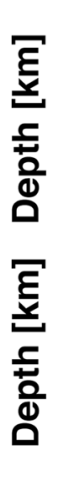

. 


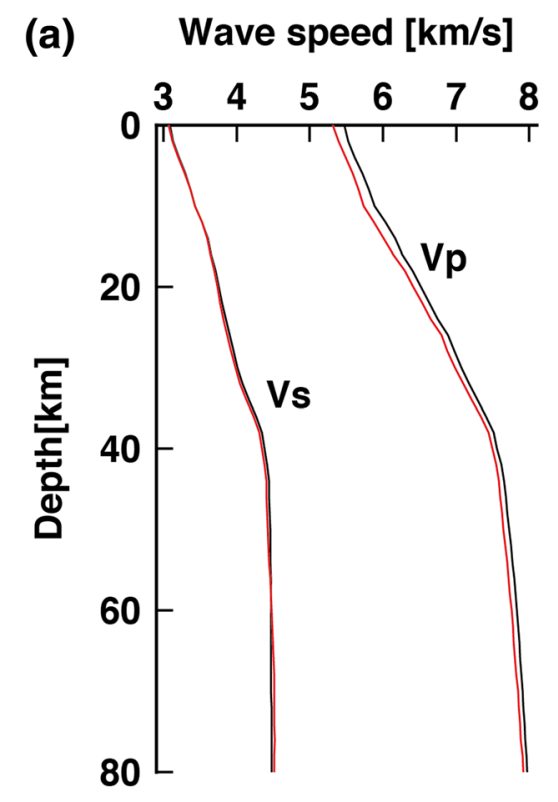

(b)

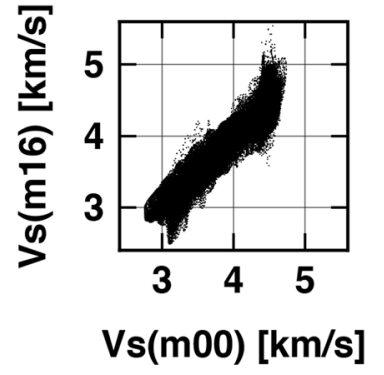

(c)

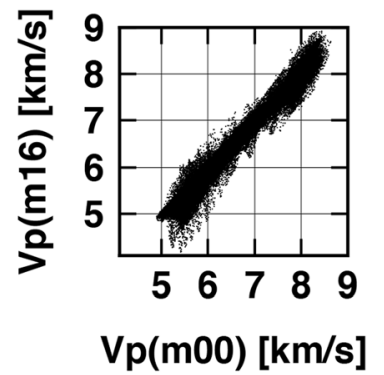

Fig. 10 Results of seismic wave speed changes. a Average wave speed of $V_{s}$ and $V_{p}$ concerning depth. Black and red lines indicate $\mathbf{m}_{00}$ and $\mathbf{m}_{16}$, respectively. $\mathbf{b}$ Comparison of $V_{s}$ values of $\mathbf{m}_{00}$ and $\mathbf{m}_{16}$. $\mathbf{c}$ Comparison of $V_{p}$ values of $\mathbf{m}_{00}$ and $\mathbf{m}_{16}$

(a)
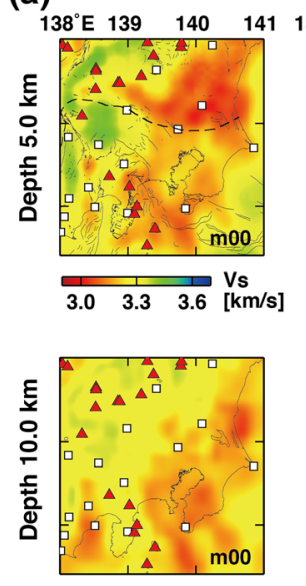

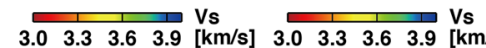
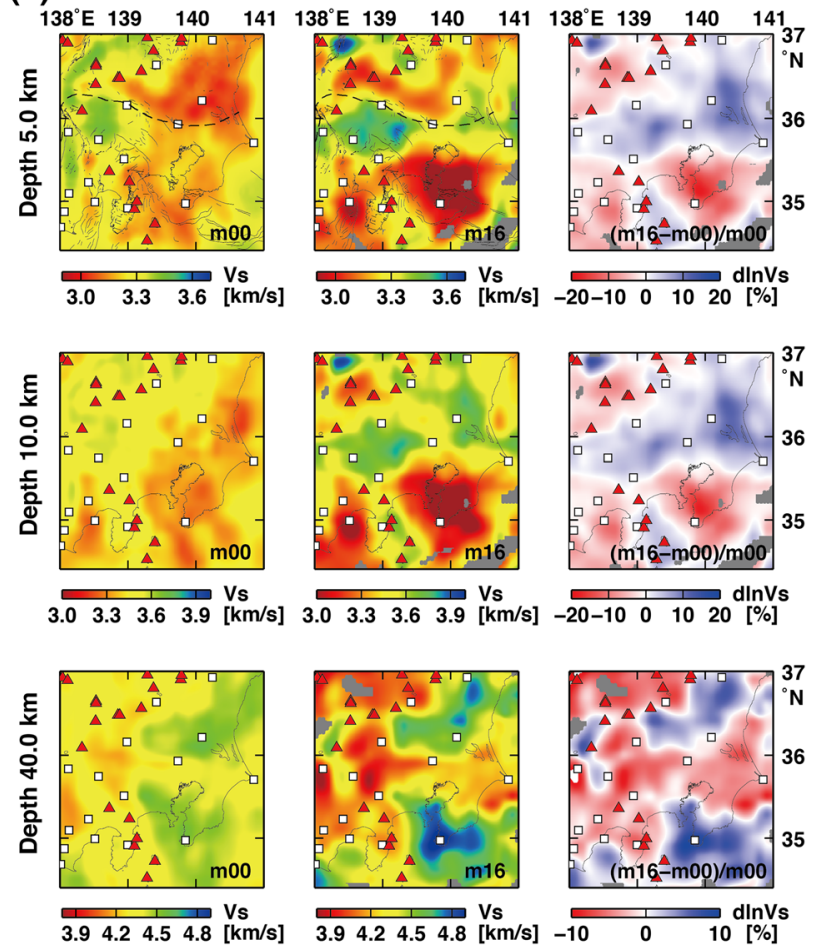

(b)
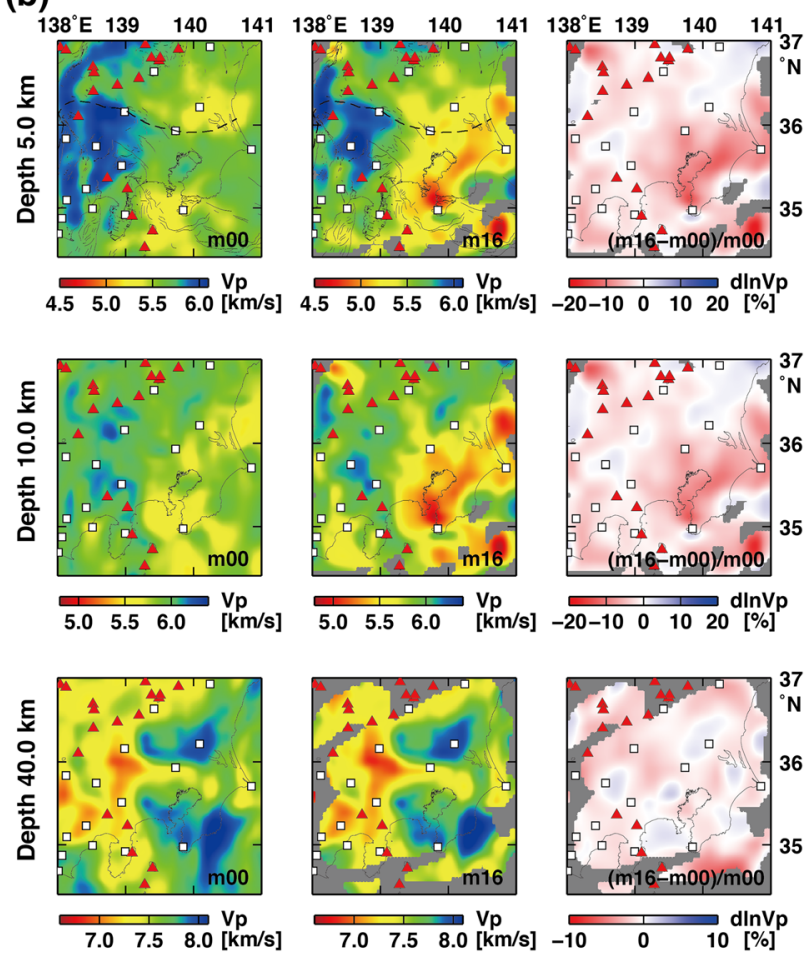

Fig. 11 Depth slices concerning the seismic wave speed model. a $V_{s}$ and $\mathbf{b} V_{p}$ models. The left, center, and right panels show the wave speed of $\mathbf{m}_{00}$, the wave speed of $\mathbf{m}_{16}$, and the difference between the wave speeds of $\mathbf{m}_{00}$ and $\mathbf{m}_{16}$. Open squares and red triangles represent F-net stations and volcanoes, respectively. In (a), active faults and the MTL are shown as black lines and a broken line, respectively 

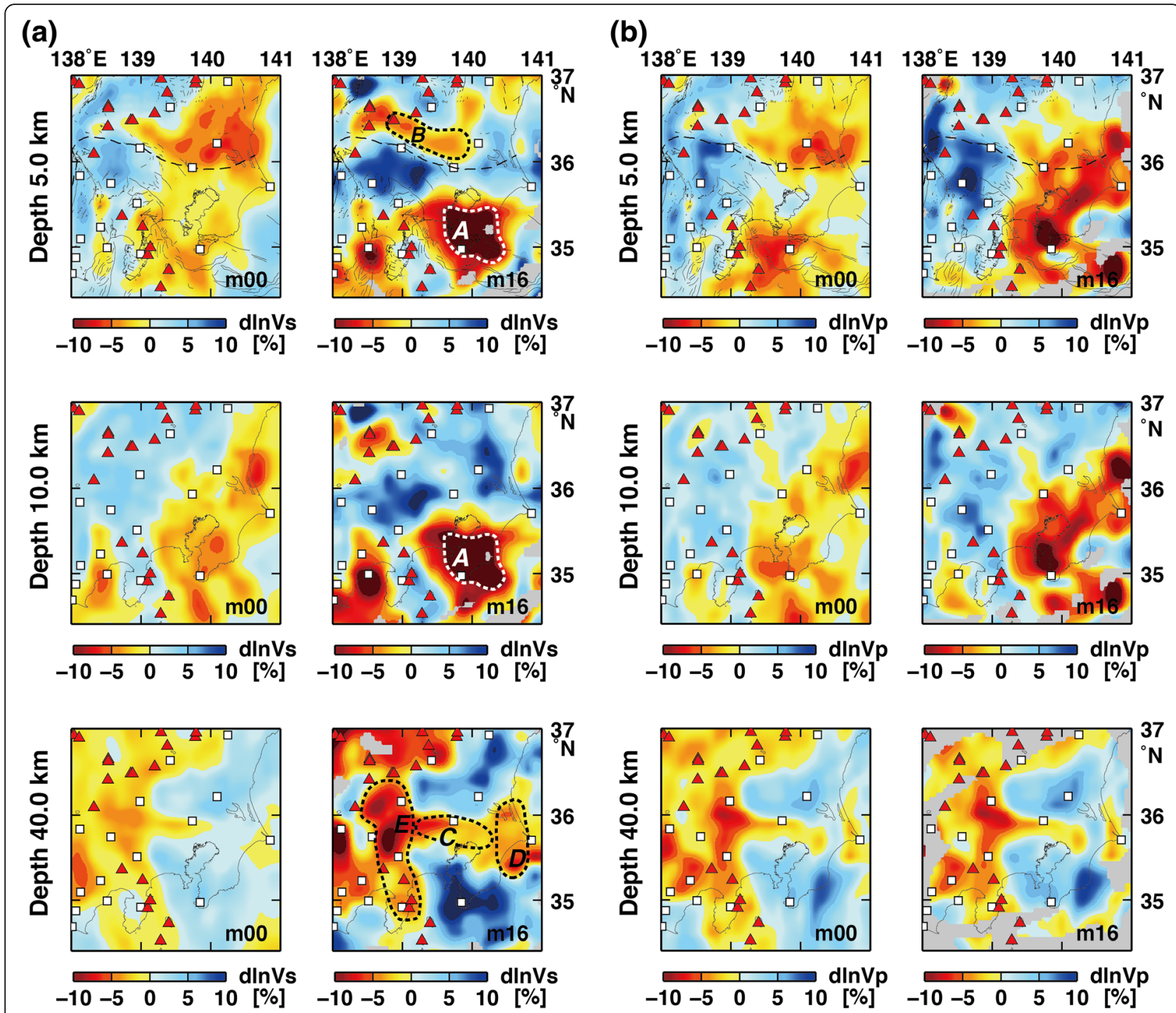

Fig. 12 Depth slices of the perturbation of the seismic wave speed from the average speed. $\mathbf{a} V_{s}$ and $\mathbf{b} V_{p}$ models. The left and right panels indicate the perturbations of the wave speeds for $\mathbf{m}_{00}$ and $\mathbf{m}_{16}$, respectively. Areas labeled $A$ to $E$ in the right figures indicate low-wave speed anomalies. Other aspects of the figure are the same as in Fig. 11

second was NW of the first (B in Fig. 12a). The first area was not detected clearly in $\mathbf{m}_{00}$ and appeared to be contiguous to the low- $V_{s}$ area at a depth of $10 \mathrm{~km}$. At a depth $40 \mathrm{~km}$, low seismic wave speed patterns were observed more clearly in $\mathbf{m}_{16}$ than in $\mathbf{m}_{00}$ and were distinct in the $\mathrm{E}-\mathrm{W}$ (C in Fig. 12a) and $\mathrm{N}-\mathrm{S}$ (D and $\mathrm{E}$ in Fig. 12a) directions. Regarding the $V_{p}$ deviation shown in Fig. 12b, low-wave speeds were obtained in the eastern part of the model region, whereas the western part of the model region showed high-wave speeds at depths of 5.0 and $10.0 \mathrm{~km}$. The deviation of $V_{p}$ from the average had a similar pattern to that of $V_{s}$ at a depth of $40 \mathrm{~km}$. The following section discusses the tectonic significance of these extremely low-wave speed areas.

\section{Discussion}

\section{Validation of proposed model}

One of the purposes of the model developed in the present study is to predict the waveforms of earthquakes that occur beneath the Kanto region. To verify the proposed model, 18 additional event data that were not considered in the inversion were examined. Additional forward simulations concerning $\mathbf{m}_{00}$ and $\mathbf{m}_{16}$ were conducted for the 18 extra events. The full-waveform fitting of the synthetic waveforms to the observation data is 

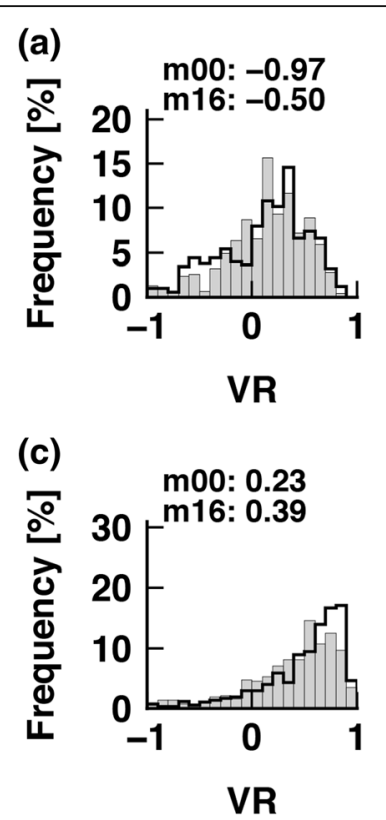
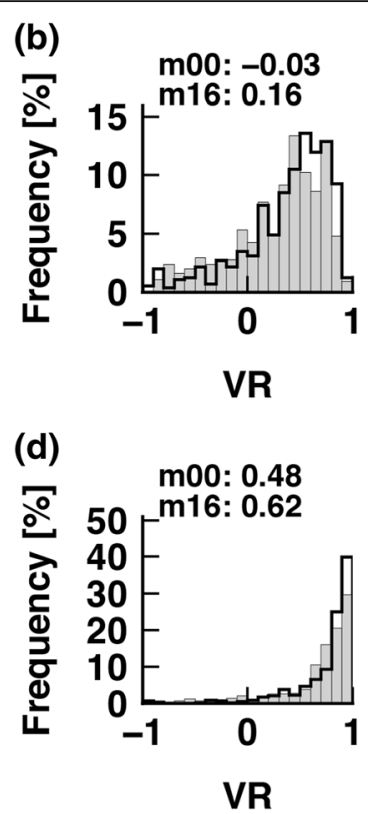

Fig. 13 Waveform fitting for extra events. a 5-30 s, b 8-30 s, c 10-30 s, and $\mathbf{d} 20-30$ s. The gray bars and black outlines indicate the VR values of $\mathbf{m}_{00}$ and $\mathbf{m}_{16}$, respectively. The average VR values are also shown in each panel

shown in Fig. 13. The final model $\mathbf{m}_{16}$ better reproduced the observation than the initial model $\mathbf{m}_{00}$, and the synthetic waveforms in the longer period range showed better fitting than those in the shorter period range. The VR value in the period range of 5-30 s was improved by $47 \%$, corresponding to change from -0.97 to -0.50 for the $\mathbf{m}_{00}$ and $\mathbf{m}_{16}$ waveforms, respectively. Figure 14 shows a comparison of the observed and synthetic waveforms for an earthquake occurring in the upper crust and a vertical cross section of the shear wave speed structure. The transverse and vertical components of the S-waves for $\mathbf{m}_{16}$ were better fit than those for $\mathbf{m}_{00}$ to the observed waveform. The proposed model did not reproduce the observed waveforms after body waves, such as surface waves derived from the basin (Fig. 14) because no windows were set around the surface waves, which indicated that the wave speed model could still be improved with future research.

Figure 15 shows the event profiles of the vertical components of waveforms at different epicentral distances for the events used in the inversion and an extra event that was not used in the inversion. The synthetic waveforms for $\mathbf{m}_{16}$ were better fit than those for $\mathbf{m}_{00}$ to the observed waveforms except for the waveforms after $\mathrm{S}$ wave arrivals (Fig. 15b). The proposed model still overestimates the amplitudes of the local surface waves. However, the inversion appeared to have accurately reproduced the body waves. These results indicated that the proposed model had great potential to model the waveforms of past and future earthquakes and that the redetermination of source parameters using the time shift was an adequate technique for correcting the centroid time in the inversion. Furthermore, this improved model was obtained using the waveforms of 140 sources recorded at only 16 broadband stations.

\section{Data coverage and resolution}

The parameters of the seismic wave speed were revised at all grid points throughout the model region. It is well known that there is only waveform sensitivity around the ray paths between sources and receivers. The misfit kernels were calculated using the theoretical $\mathbf{m}_{16}$ waveforms and deviation waveforms of $\mathbf{m}_{16}$ to determine the data coverage in the present study. A $1.0 \mathrm{~s}$ phase shift anomaly concerning the theoretical waveforms of $\mathbf{m}_{16}$ was included, and the misfit kernels were calculated by assuming the observed waveforms were perturbed waveforms. The obtained misfit kernels of $V_{p}$ and $V_{s}$ were regarded to represent the data coverage of $V_{p}$ and $V_{s}$, respectively. The data coverage results are shown in Fig. 16. The kernels were normalized by a subjective value of $1.5 \times 10^{-11}$. Excluding the coverage of $V_{p}$ at a depth of $40 \mathrm{~km}$ (Fig. 16), the data used in the present study covered nearly the entire region shown in Figs. 11 and 12.

As discussed in previous waveform inversion studies, traditional checkerboard tests with a workable resolution had a high computational cost (e.g., Zhu et al. 2015). In the present study, a point-spreading function using the Hessian and model perturbation was considered (e.g., Fichtner and Trampert 2011; Zhu et al. 2015). The 


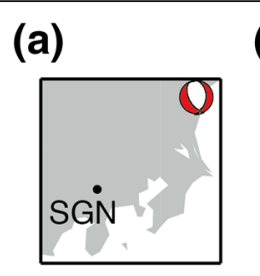

(b)
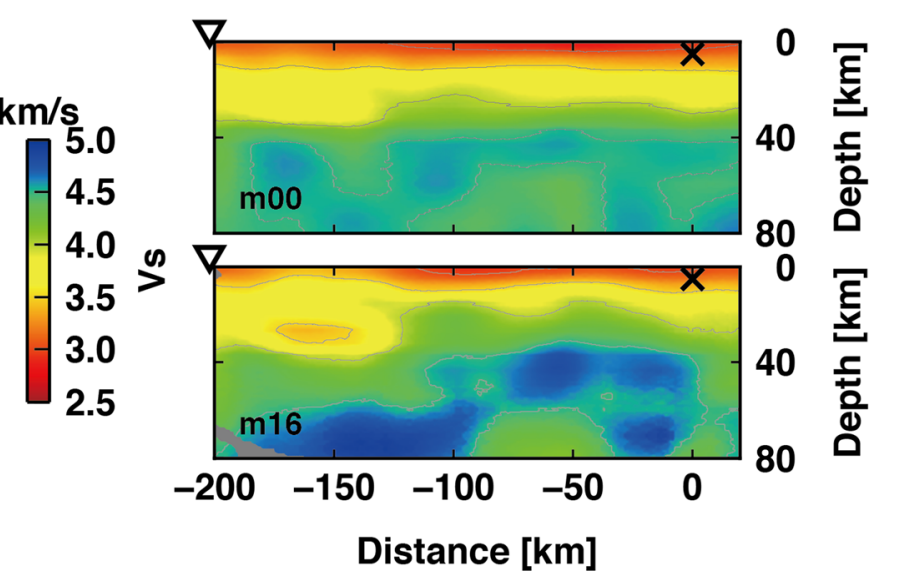

(c)

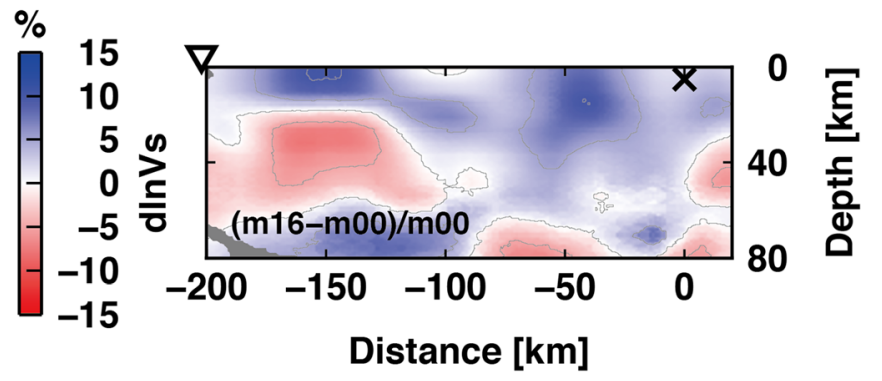

(d)
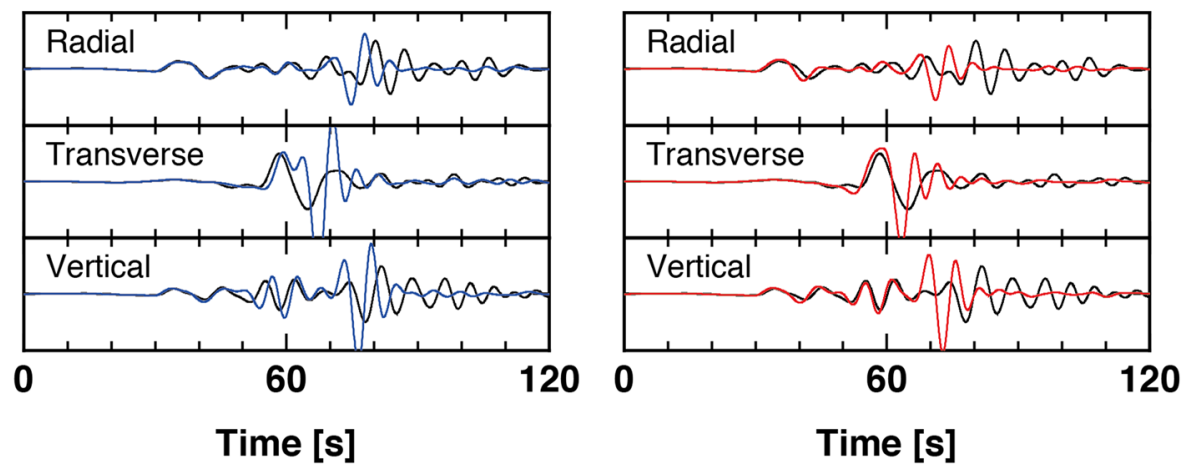

Fig. 14 Same as Fig. 8 for the wave speed models and waveforms for the extra shallow event (Feb. 19, 2012; MW 4.9). a Source and receiver. b Vertical cross section of $V_{s}$ for $\mathbf{m}_{00}$ and $\mathbf{m}_{16}$. $\mathbf{c}$ Vertical cross section of the difference between the $V_{s}$ values for $\mathbf{m}_{00}$ and $\mathbf{m}_{16}$. $\mathbf{d}$ Waveform comparisons. The gray areas in (b) and (c) indicate areas of low data coverage. The crosses and inverted triangles in (b) and (c) show the location of the earthquake and station in (a), respectively. The black, blue, and red lines in (d) indicate the observed, $\mathbf{m}_{00}$, and $\mathbf{m}_{16}$ waveforms, respectively

gradient of the misfit for model $\mathbf{m}+\delta \mathbf{m}$ perturbed from model $\mathbf{m}$ was considered to examine the model resolution. The gradient of the misfit is given by

$$
g(\boldsymbol{m}+\delta \boldsymbol{m}) \approx g(\boldsymbol{m})+H(\boldsymbol{m}) \delta \mathbf{m} .
$$

If model $\mathbf{m}$ is the preferred model, the gradient $g(\mathbf{m})$ nearly equals zero, and Eq. (7) can be rewritten as

$$
g(\boldsymbol{m}+\delta \boldsymbol{m}) \approx H(\boldsymbol{m}) \delta \mathbf{m} .
$$

According to Eq. (8), we must access the full Hessian $H(\mathbf{m})$ or obtain the gradient of the misfit function on the model $\mathbf{m}+\delta \mathbf{m}$ to know the resolution. In this study, $\tilde{H}(\boldsymbol{m})$ was used to avoid additional computational costs. This approach was expected to provide a first approximate guess of the spreading. Future work is needed to conduct a more thorough resolution analysis (e.g., Fichtner 2010; Zhu et al. 2015). Although the gradient of the misfit generally represented the pattern of the difference between the old and new models, the action $\tilde{H}(\mathbf{m}) \delta \mathbf{m}$ of the Hessian with respect to the model perturbation was considered as a substitute for $g(\mathbf{m}+\delta \mathbf{m})$ based on Eq. (8). Two cases of the point-spreading test were conducted based on Eq. (8) in the area of interest, 


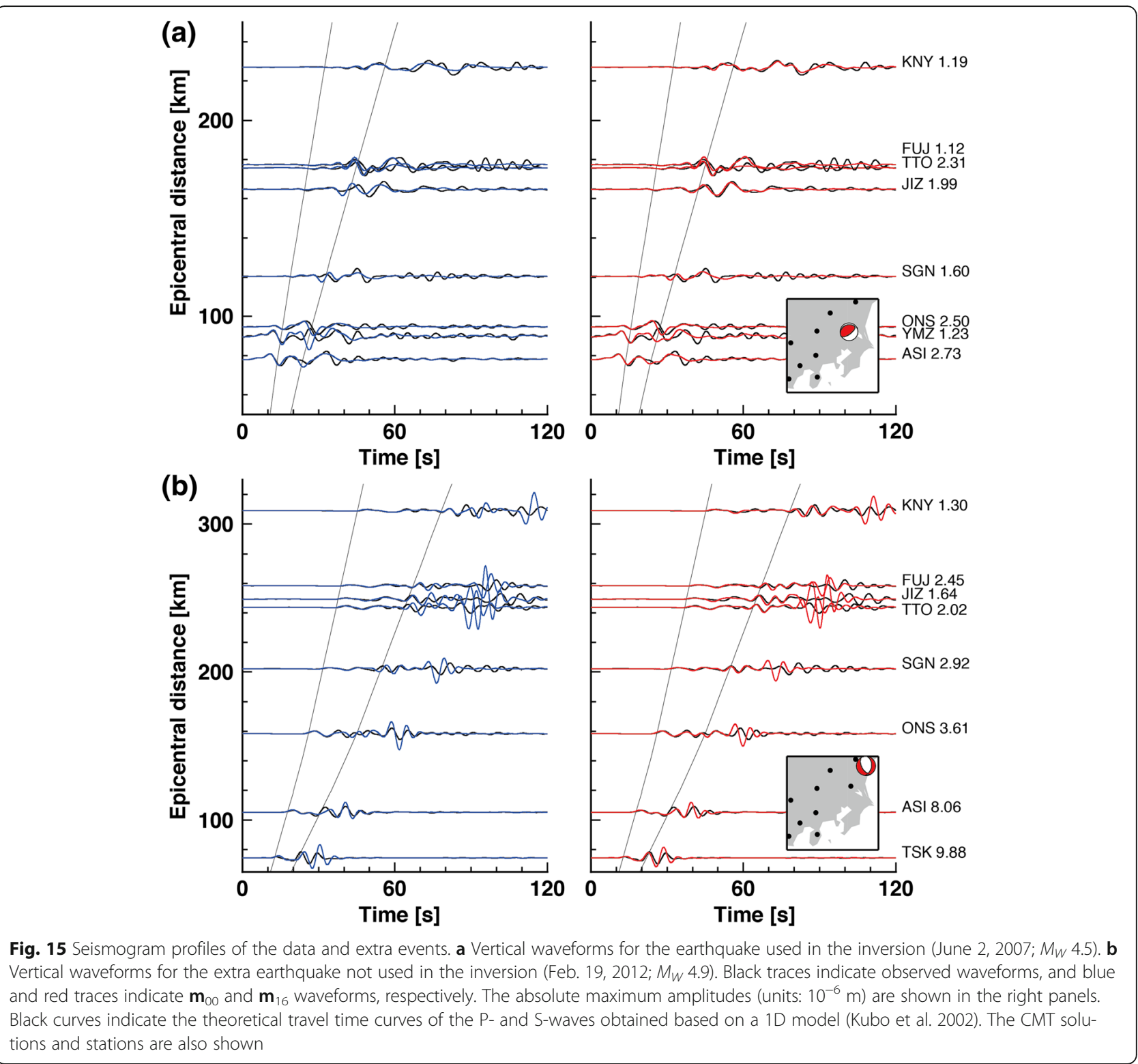

as shown in Fig. 17. The perturbation to the final model $\mathbf{m}_{16}$ was applied at depths of 40 and $5 \mathrm{~km}$ in the lowwave speed area. In both of these test cases, the perturbation patterns remained unchanged and indicated that the proposed model was well constrained. However, it must be considered that the position of the maximum $\tilde{H}(\mathbf{m}) \delta \mathbf{m}$ shifted to the surface in Fig. 17 because of the large values of the Hessian near the surface. Furthermore, the absolute value of the maximum $\tilde{H}(\mathbf{m}) \delta \mathbf{m}$ is rather small (Fig. 17a, b). Although the wide sensitivity of the misfit kernels required numerous iterations to obtain a sufficiently accurate model, the Hessian was applied as a preconditioning operator in the present study to avoid slow recovery.

\section{Tectonic interpretation of the proposed model}

This subsection focuses on the shear wave structure shown in Fig. 12a and presents a tectonic interpretation of the proposed model. A low-wave speed zone in the E-W direction was observed at a depth of $40 \mathrm{~km}$ on $\mathbf{m}_{16}\left(\mathrm{C}\right.$ in Fig. 12a) and identified as the $V_{p}$ structure on $\mathbf{m}_{00}$ and $\mathbf{m}_{16}$ (Fig. 12b). In the proposed model, this anomalously low-wave speed was lower and clearer than that in $\mathbf{m}_{00}$. As reported in previous studies, the lowwave speed anomaly around a depth of $40 \mathrm{~km}$ was considered to be serpentinized peridotite in the mantle above the subducted PHS plate beneath the Kanto region (e.g., Kamiya and Kobayashi 2000; Matsubara et al. 2005; Nakajima et al. 2009). Additional low-wave speed 

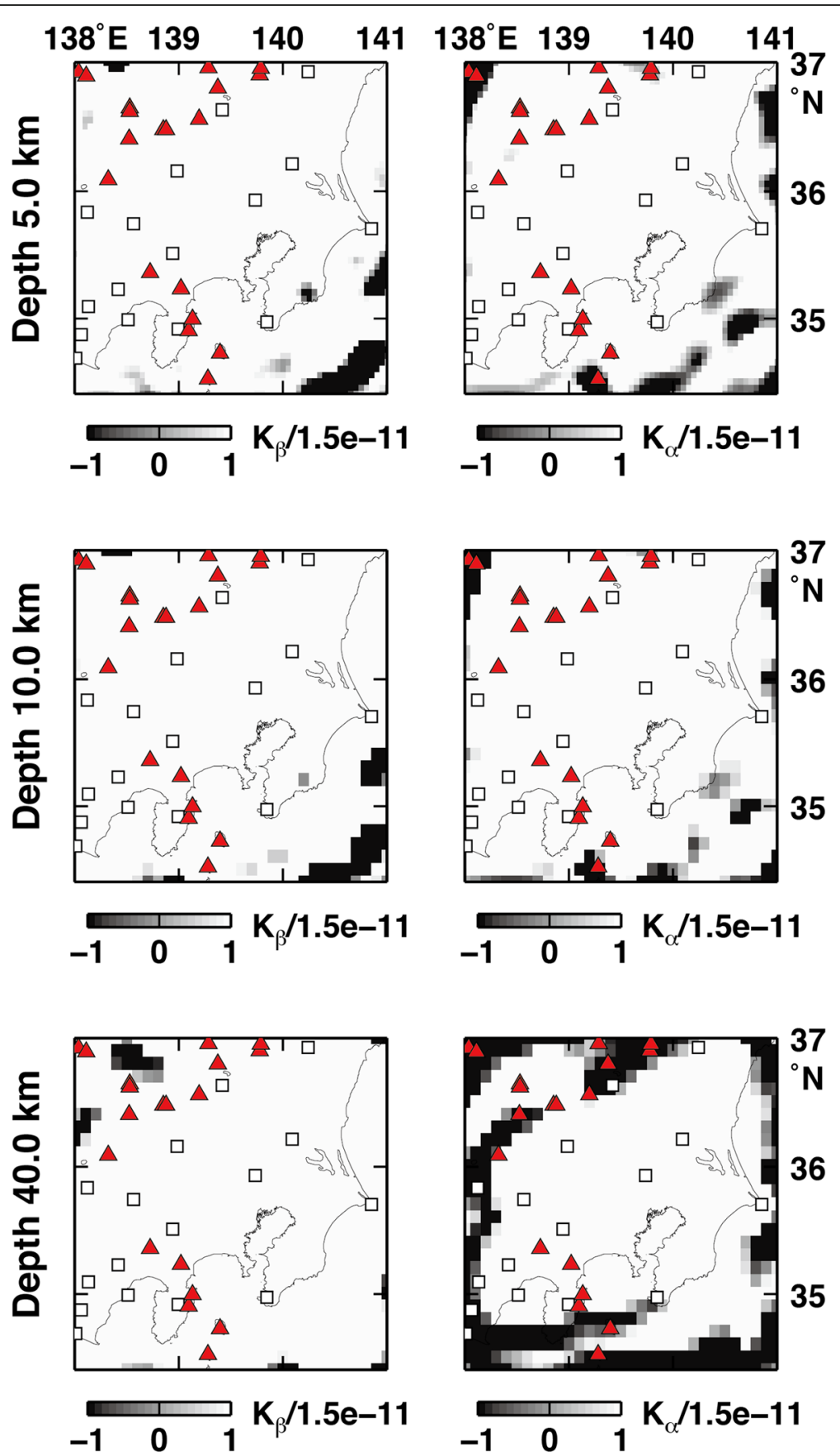

Fig. 16 Data coverage concerning seismic wave speed. The left and right figures indicate the coverage of $V_{s}$ and $V_{p}$, respectively. The kernels were normalized by a subjective value of $1.5 \times 10^{-11}$. Open squares and red triangles indicate F-net stations and volcanoes, respectively

anomalies were identified in the northern part of the Boso Peninsula (D in Fig. 12a) and along the volcano chain at a depth of $40 \mathrm{~km}$ (E in Fig. 12a). Nakajima et al. (2009) interpreted anomaly D as the serpentinized mantle of the PHS slab above the PAC slab, which was associated with lack of interplate earthquakes on the PAC slab. Anomaly $\mathrm{E}$ has also been described in previous studies (e.g., Matsubara et al. 2005; Nakajima et al. 2009) and was interpreted as the result of the dehydration reaction caused by the subduction of the PAC plate. The anomaly may be associated with volcanic generation and activity.

The low-wave speed anomaly areas at depths of 5.0 and $10.0 \mathrm{~km}$ ( $\mathrm{A}$ and $\mathrm{B}$ in Fig. 12a) mentioned in a 


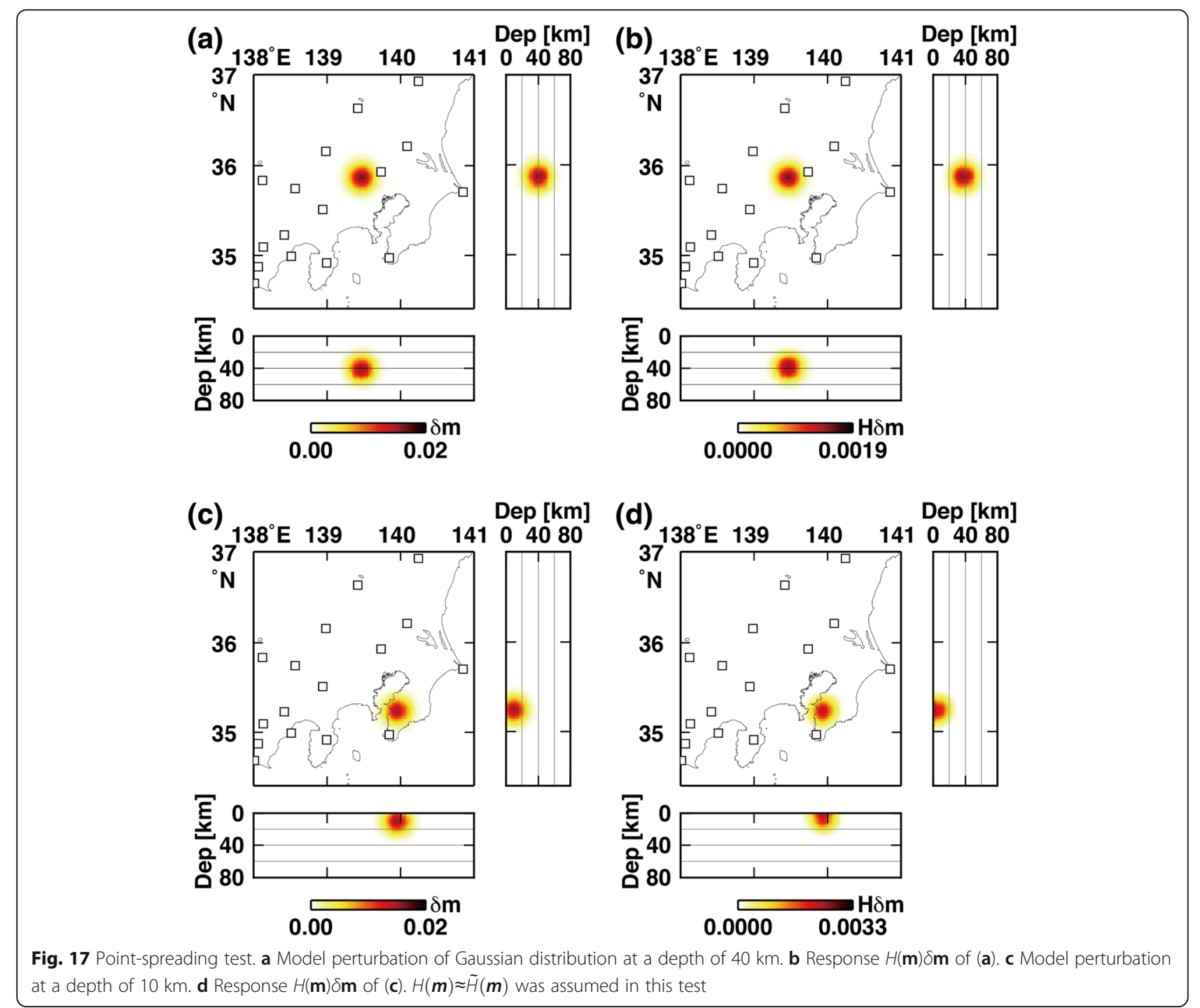

previous section are discussed here. The shear wave speed at anomaly A was approximately $10 \%$ lower than the average speed beneath the Boso Peninsula. This trend was identified in the horizontal slices of the compressional wave speed (Fig. 12b). The area of anomaly A roughly matched the structure of the Kanto basin (e.g., Suzuki 1996) and the upper part of the subducting PHS plate (e.g., Ishida 1992). Anomaly B extended in the NW-SE direction along the active faults. It was continuous to the north, and its eastern edge met a high-wave speed anomaly near the TSK station. These low-wave speed features were in good agreement with the topography of the lowland (Fig. 1). Anomaly B was also contiguous to the northwestern part, and its strike appeared to change to the NE-SW direction in the northern area of the Izu Peninsula. This implied that it was related to the lateral bending of the Median Tectonic Line and zonal geologic terrains associated with the collision tectonics of the opening of the Japan Sea in the Middle Miocene and the migration of the PHS plate that occurred until $6 \mathrm{Ma}$ (Takahashi and Saito 1997). Although the travel time tomography results have not revealed such an anomaly at a shallow depth, adjoint tomography using waveforms demonstrated the characteristics of an anomaly associated with the surface geology. The present results still have low resolution because the period range of waveforms must be longer than those used to study the case of California (e.g., Tape et al. 2010) to provide a detailed structure. A detailed model with high resolution could be obtained by using more data and seismograms of shorter period range to contribute to strong motion predictions by reproducing entire waveforms, including surface waves generated from the basin structure. 


\section{Conclusions}

A 3D seismic wave speed model capable of reproducing observed seismograms using adjoint tomography beneath the Japanese metropolitan area in the Kanto region was successfully developed. The optimized SEM code on the $\mathrm{K}$ computer required a total of 6720 simulations using approximately 62,000 node hours to obtain the final model through 16 iterations. The fit of the synthetic waveforms to the observed waveforms was improved using the proposed model, by 24 and $47 \%$ relative to the fit of the original model with full waves in the period range of 5-30 s for inversion data and extra data, respectively. These results indicated that the proposed model had the potential to evaluate waveforms of past and future earthquakes reliably and that source relocation using the time shift was an adequate technique for correcting centroid time in the inversion. Additionally, this improved model was obtained using the waveforms of 140 sources recorded at only 16 broadband stations. The wave speeds $V_{s}$ and $V_{p}$ of the proposed model were changed by approximately 20 and $10 \%$, respectively, from those of the initial model. The proposed model showed strong heterogeneity compared with the initial model at each depth slice. Areas with anomalously low-wave speeds were detected, and detection was supported by the analysis of data coverage and point spreading. In combination with the results of previous studies, our results indicated that the detected extreme anomalies were located at the bottom of the Kanto basin on top of the PHS slab at a depth of $5 \mathrm{~km}$, at the serpentinized mantle above the PHS slab at a depth of $40 \mathrm{~km}$, and at the partial melting beneath the volcanoes at a depth of $40 \mathrm{~km}$.

\section{Abbreviations}

FREESIA: Fundamental Research on Earthquakes and Earth's Interior Anomaly; NIED: National Research Institute for Earth Science and Disaster Resilience; PAC: Pacific; PHS: Philippine Sea; SEM: Spectral-element method

\section{Acknowledgements \\ We appreciate the valuable discussions we had with Kazuto Ando, Daisuke Suetsugu, and Nozomu Takeuchi. We used the seismic waveform and earthquake catalog provided by the NIED F-net. Digital map $50 \mathrm{~m}$ grid elevation data and the J-EGG500 were provided by the Geospatial Information Authority of Japan and the Japan Oceanographic Data Center, respectively. The large computing of the forward and adjoint simulations was conducted on the K computer at the RIKEN Advanced Institute for Computational Science in Kobe, Japan. We used the open source program package SPECFEM3D Cartesian and FLEXWIN from the Computational Infrastructure for Geodynamics (CIG; geodynamics.org) in this study. GMT software (Wessel and Smith 1998) was used to make most of the figures in this paper.}

\section{Funding}

This work was supported by the HPCI System Research project (Proposal number hp130013), JSPS KAKENHI Grant Number 16K21699, and MEXT KAKENHI Grant Number 15H05832.

\section{Authors' contributions}

TM designed this study, conducted most of the computing and analysis, and wrote the manuscript. MO and DP assisted with the data processing and large computing. YT took part in the analysis of the observed data.
ST assisted with the large computing. All authors read and approved the final manuscript.

\section{Competing interests}

The authors declare that they have no competing interests.

\section{Publisher's Note}

Springer Nature remains neutral with regard to jurisdictional claims in published maps and institutional affiliations.

\section{Author details}

${ }^{1}$ Earthquake Research Institute, University of Tokyo, 1-1-1 Yayoi, Bunkyo-ku, Tokyo 113-0032, Japan. ${ }^{2}$ Present address: Earthquake and Tsunami Research Division, National Research Institute for Earth Science and Disaster Resilience, 3-1 Tennodai, Tsukuba, Ibaraki 305-0006, Japan. ${ }^{3}$ Department of Deep Earth Structure and Dynamics Research, Japan Agency for Marine-Earth Science and Technology, 2-15 Natsushima-cho, Yokosuka, Kanagawa 237-0061, Japan. ${ }^{4}$ Physical Sciences and Engineering Division, King Abdullah University of Science and Technology, Thuwal 23955-6900, Kingdom of Saudi Arabia. ${ }^{5}$ Research and Development Bureau, Ministry of Education, Culture, Sports, Science and Technology, 3-2-2 Kasumigaseki, Chiyoda-ku, Tokyo 100-8959, Japan. ${ }^{6}$ Center for Earth Information Science and Technology, Japan Agency for Marine-Earth Science and Technology, 3173-25 Showa-machi, Kanazawa-ku, Yokohama, Kanagawa 236-0001, Japan.

Received: 21 March 2017 Accepted: 21 September 2017

Published online: 03 October 2017

\section{References}

Bozdag E, Peter D, Lefebvre M, Komatitsch D, Tromp J, Hill J, Podhorszki N, Pugmire D (2016) Global adjoint tomography: first-generation model. Geophys J Int 207:1739-1766. doi:10.1093/gji/ggw356

Brocher T (2005) Empirical relations between elastic wavespeeds and density in the Earth's crust. Bull Seism Soc Am 95:2081-2092

Chen M, Niu F, Liu Q, Tromp J, Zheng X (2015) Multiparameter adjoint tomography of the crust and upper mantle beneath East Asia: 1. Model construction and comparisons. J Geophys Res Solid Earth 120:1762-1786. doi:10.1002/2014JB011638

Clayton R, Engquist B (1977) Absorbing boundary conditions for acoustic and elastic wave equations. Bull Seism Soc Am 67:1529-1540

Fichtner A (2010) Full seismic waveform modelling and inversion. SpringerVerlag, Heidelberg

Fichtner A, Kennett B, lgel H, Bunge H (2009) Full seismic waveform tomography for upper-mantle structure in the Australasian region using adjoint methods. Geophys J Int 179:1703-1725. doi:10.1111/j.1365-246X.2009.04368.x

Fichtner A, Trampert J (2011) Resolution analysis in full waveform inversion. Geophys J Int 187:1604-1624. doi:10.1111/j.1365-246X.2011.05218.x

Gardner GHF, Gardner LW, Gregory AR (1974) Formation velocity and density - the diagnostic basics for stratigraphic traps. Geophys 39:770-780

Geller R, Hara T (1993) Two efficient algorithms for iterative linearized inversion of seismic waveform data. Geophys J Int 115:699-710. doi:10.1111/j.1365-246X. 1993.tb01488.x

Hori S (2006) Seismic activity associated with the subducting motion of the Philippine Sea plate beneath the Kanto district, Japan. Tectonophysics 417:85-100

Ishida M (1992) Geometry and relative motion of the Philippine Sea Plate and Pacific Plate beneath the Kanto-Tokai District, Japan. J Geophys Res 97:489-513. doi:10.1029/91JB02567

Kamiya S, Kobayashi Y (2000) Seismological evidence for the existence of serpentinized wedge mantle. Geophysical Res Lett 27:819-822

Kamiya S, Kobayashi Y (2007) Thickness variation of the descending Philippine Sea slab and its relationship to volcanism beneath the Kanto-Tokai district, central Japan. J Geophys Res 112:B06302. doi:10.1029/2005JB004219

Kimura T, Murakami H, Matsumoto T (2015) Systematic monitoring of instrumentation health in high-density broadband seismic networks. Earth Planet Space 67:55. doi:10.1186/s40623-015-0226-y

Koketsu K, Miyake H, Afnimar TY (2009) A proposal for a standard procedure of modeling 3-D velocity structures and its application to the Tokyo metropolitan area, Japan. Tectonophysics 472:290-300

Koketsu K, Miyake H, Fujiwara H, Hashimoto T (2008) Progress towards a Japan integrated velocity structure model and long-period ground motion hazard 
map. Proceedings of the 14th world conference on earthquake engineering, pp S10-038

Komatitsch D, Tromp J (2002a) Spectral-element simulations of global seismic wave propagation-I. Validation. Geophys J Int 149:390-412

Komatitsch D, Tromp J (2002b) Spectral-element simulations of global seismic wave propagation-II. Three-dimensional models, oceans, rotation and selfgravitation. Geophys J Int 150:303-318

Kubo A, Fukuyama E, Kawai H, Nonomura K (2002) NIED seismic moment tensor catalogue for regional earthquakes around Japan: quality test and application. Tectonophysics 356:23-48

Maggi A, Tape C, Chen M, Chao D, Tromp J (2009) An automated time-window selection algorithm for seismic tomography. Geophys J Int 178:257-281. doi:10.1111/j.1365-246X.2009.04099.x

Matsubara M, Hayashi H, Obara K, Kasahara K (2005) Low-velocity oceanic crust at the top of the Philippine Sea and Pacific plates beneath the Kanto region, central Japan, imaged by seismic tomography. J Geophys Res 110:B12304. doi:10.1029/2005JB003673

Matsubara M, Obara K (2011) The 2011 off the Pacific coast of Tohoku Earthquake related to a strong velocity gradient with the Pacific plate. Earth Planet Space 63:663-667

Matsumura M, Ito Y, Kimura H, Obara K, Sekiguchi S, Hori S, Kasahara K (2006) Development of accurate and quick analysis system for source parameters (AQUA). Zishin 59:167-184 (in Japanese with English abstract)

Montagner J, Anderson D (1989) Petrological constraints on seismic anisotropy. Phys Earth Planet Inter 54:82-105

Nakajima J, Hasegawa A (2010) Cause of M 7 intraslab earthquakes beneath the Tokyo metropolitan area, Japan: possible evidence for a vertical tear at the easternmost portion of the Philippine Sea slab. J Geophys Res 115: B04301. doi:10.1029/2009JB006863

Nakajima J, Hirose F, Hasegawa A (2009) Seismotectonics beneath the Tokyo metropolitan area, Japan: effect of slab-slab contact and overlap on seismicity. J Geophys Res 114:B08309. doi:10.1029/2008JB006101

Okada Y, Kasahara K, Hori S, Obara K, Sekiguchi S, Fujiwara H, Yamamoto A (2004) Recent progress of seismic observation networks in Japan -Hi-net, F-net, KNET and KiK-net-. Earth Planet Space 56:xv-xxviii

Olsen KB, Day SM, Bradley CR (2003) Estimation of Q for long-period (>2 sec) waves in the Los Angeles basin. Bull Seismol Soc Am 93:627-638

Panning M, Romanowicz B (2006) A three-dimensional radially anisotropic model of shear velocity in the whole mantle. Geophys J Int 167:361-379

Patera AT (1984) A spectral element method for fluid dynamics: laminar flow in a channel expansion. J Comput Phys 54:468-488

Peter D, Komatitsch D, Luo Y, Martin R, Goff N, Casarotti E, Loher P, Magnoni F, Liu Q Blitz C, Nissen-Meyer T, Basini P, Tromp J (2011) Forward and adjoint simulations of seismic wave propagation on fully unstructured hexahedral meshes. Geophys J Int 186:721-739. doi:10.1111/j.1365-246X.2011.05044.x

Plessix RE (2006) A review of the adjoint-state method for computing the gradient of a functional with geophysical applications. Geophys J Int 167: 495-503. doi:10.1111/j.1365-246X.2006.02978.x

Simute S, Steptoe H, Cobden L, Gokhverg A, Fichtner A (2016) Full-waveform inversion of the Japanese Islands region. J Geophys Res Solid Earth 121: 3722-3741. doi:10.1002/2016JB012802

Suzuki H (1996) Geology of the Koto deep borehole observatory and geological structure beneath the metropolitan area, Japan. Rep Natl Res Inst Earth Sci Disaster Prev 56:77-123 (in Japanese with English abstract)

Takahashi M, Saito K (1997) Miocene intra-arc bending at an arc-arc collision zone, central Japan. Island Arc 6:168-182

Tape C, Liu Q, Maggi A, Tromp J (2009) Adjoint tomography of the southern California crust. Science 325:988-992. doi:10.1126/science.1175298

Tape C, Liu Q, Maggi A, Tromp J (2010) Seismic tomography of the southern California crust based on spectral-element and adjoint methods. Geophys J Int 180:433-462. doi:10.1111/j.1365-246X.2009.04429.x

Tape C, Liu Q, Tromp J (2007) Finite-frequency tomography using adjoint methods-Methodology and examples using membrane surface waves. Geophys J Int 168:1105-1129. doi:10.1111/j.1365-246X.2006.03191.x

Tarantola A (1984) Inversion of seismic reflection data in the acoustic approximation. Geophysics 49:1259-1266

Tarantola A (1986) A strategy for nonlinear elastic inversion of seismic reflection data. Geophysics 51:1893-1903

Tromp J, Tape C, Liu Q (2005) Seismic tomography, adjoint methods, time reversal and banana-doughnut kernels. Geophys J Int 160:195-216. doi:10.1111/j.1365-246X.2004.02453.x
Tsuboi S, Ando K, Miyoshi T, Peter D, Komatitsch D, Tromp J (2016) A 1.8 trillion degreesof-freedom, 1.24 petaflops global seismic wave simulation on the K computer. Int J High Perform Comput Appl 30:411-422. doi:10.1177/1094342016632596

Wang Y, Chevrot S, Monteiller V, Komatitsch D, Mouthereau F, Manatschal G, Sylvander M, Diaz J, Ruiz M, Grimaud F, Benahmed S, Pauchet H, Martin R (2016) The deep roots of the western Pyrenees revealed by full waveform inversion of teleseismic P waves. Geology 44:475-478. doi:10.1130/G37812.1

Wessel P, Smith WHF (1998) New, improved version of the Generic Mapping Tools released. EOS Trans AGU 79:579. doi:10.1029/90EO00426

Yoshimoto K, Takemura S (2014) Surface wave excitation at the northern edge of the Kanto Basin, Japan. Earth Planet Space 66. doi:10.1186/1880-5981-66-16

Zhou Y, Dahlen F, Nolet G (2004) Three-dimensional sensitivity kernels for surface wave observables. Geophys J Int 158:142-168. doi:10.1111/j.1365-246X.2004.02324.X

Zhu H, Bozdag E, Peter D, Tromp J (2012) Structure of the European upper mantle revealed by adjoint tomography. Nat Geosci 5:493-498. doi:10.1038/NGEO1501

Zhu H, Bozdag E, Tromp J (2015) Seismic structure of the European upper mantle based on adjoint tomography. Geophys J Int 201:18-52. doi:10.1093/gji/ggu492

Zhu H, Tromp J (2013) Mapping tectonic deformation in the crust and upper mantle beneath Europe and the north Atlantic Ocean. Science 341:871-875. doi:10.1126/science.1241335

\section{Submit your manuscript to a SpringerOpen ${ }^{\circ}$ journal and benefit from:}

- Convenient online submission

- Rigorous peer review

- Open access: articles freely available online

- High visibility within the field

- Retaining the copyright to your article

Submit your next manuscript at $\gg$ springeropen.com 